\title{
Low-carbon roadmap of chemical production: A case study of ethylene in China
}

\author{
Zhitong Zhao a,b,c ${ }^{\text {, }}$ Katie Chong ${ }^{d}$, Jingyang Jiang ${ }^{c}$, Karen Wilson ${ }^{d}$, Xiaochen Zhang ${ }^{\text {a }}$, Feng Wang ${ }^{\mathrm{a}, *}$ \\ a State Key Laboratory of Catalysis, Dalian National Laboratory for Clean Energy, Dalian Institute of Chemical Physics, \\ Chinese Academy of Sciences, Dalian 116023, P. R. China. \\ ${ }^{\mathrm{b}}$ University of the Chinese Academy of Sciences, Beijing 100049, P. R. China \\ c State Key Laboratory of Fine Chemicals, College of Chemistry, Faculty of Chemical Environmental and Biological \\ Science and Technology, Dalian University of Technology, Dalian 116024, P. R. China \\ ${ }^{\mathrm{d}}$ European Bioenergy Research Institute, Aston University, Birmingham B4 7ET, UK
}

\section{ABSTRACT}

The increasing emissions of carbon dioxide $\left(\mathrm{CO}_{2}\right)$ are primarily driven by the rapid expansion of energyintensive sectors such as the chemical industry. This work selects ethylene, one of the most important chemicals, as a model study to represent the low-carbon roadmap of chemical production. Four strategies, improving the efficiency of fossil resource usage, developing the technology for carbon capture and storage (CCS), $\mathrm{CO}_{2}$ chemical conversion, and converting biomass resources into chemicals, are used to reduce $\mathrm{CO}_{2}$ emissions. A comprehensive analysis of the life cycle $\mathrm{CO}_{2}$ emissions of different ethylene production routes has been performed to compare their emission reduction potential. The results indicate that the CO2MTO $\left(\mathrm{CO}_{2}\right.$ to olefins via methanol-to-olefins) pathway releases the least $\mathrm{CO}_{2}\left(-0.05 \mathrm{t} \mathrm{CO}_{2} / \mathrm{t}\right.$ ethylene), while the CFTO (coal to olefins via Fischer-Tropsch synthesis) possesses the most $\mathrm{CO}_{2}$ emissions. Combining CCS

\footnotetext{
Abbreviations: BETE, biomass to ethylene via ethanol to ethylene pathway; BMTO, biomass to olefins via methanol-to-olefins pathway; CCS, carbon capture and storage; CFTO, coal to olefins via Fischer-Tropsch to olefins pathway; CMTO, coal to olefins via methanol-to-olefins pathway; $\mathrm{CO}_{2}$, carbon dioxide; CPP, catalytic pyrolytic process; $\mathrm{CO} 2 \mathrm{MTO}, \mathrm{CO}_{2}$ to olefins via methanol-to-olefins pathway; ETE, ethanol to ethylene; FTO, Fischer-Tropsch to olefins; GHG, greenhouse gas; LCA, life cycle assessment; MEA, monoethanolamine; MTO, methanol-to-olefins; NG, natural gas; NGLs, natural gas liquids; NMTO, natural gas to olefins via methanol-to-olefins pathway; NSC, steam cracking of conventional natural gas; PSC, steam cracking of mixed petroleum; SC, steam cracking; SSC, steam cracking of shale gas; TEA, techno-economic analysis

* Corresponding author. E-mail address: wangfeng@dicp.ac.cn (F. Wang)
} 
with BMTO (biomass to olefins via methanol-to-olefins) results in $\mathrm{CO}_{2}$ emissions of $-6.0 \mathrm{t}$ per $\mathrm{t}$ ethylene. Furthermore, we analysed the annual production and $\mathrm{CO}_{2}$ emissions of ethylene in the last 17 years and integrated this real-time change with different pathways. The $\mathrm{CO}_{2}$ emissions have decreased by $29.4 \%$ per t ethylene from 2000 to 2016 in China. However, the total amount of $\mathrm{CO}_{2}$ emissions continuously increase in the ethylene production industry. Given that China has promised to hit peak $\mathrm{CO}_{2}$ emissions by 2030 , a scenario analysis was performed. To achieve this goal, the ratios of BMTO, CO2MTO or BETE (ethanol to ethylene pathway originating from biomass) pathways should increase by $0.9 \%, 1.4 \%$ and $1.6 \%$ annually from 2020, respectively. Then more than 700 million metric tons of $\mathrm{CO}_{2}$ will be eliminated from 2020 to 2040. The results highlight the pivotal role that regulation and policy administration can play in controlling $\mathrm{CO}_{2}$ emissions by increasing average technological level and turning to low-carbon routes in the chemical industry in China.

KEYWORDS: ethylene; $\mathrm{CO}_{2}$ emissions; methanol-to-olefins; life cycle assessment; biomass; scenario analysis

\section{Introduction}

Carbon dioxide $\left(\mathrm{CO}_{2}\right)$ has become the focus of world attention due to its impact on climate change [1,

2]. It has been reported that atmospheric $\mathrm{CO}_{2}$ concentration has increased from approximately $280 \mathrm{ppm}$ in 1750, at the beginning of the industrial era, to a level of 404 ppm in February of 2017 [3, 4]. The chemical industry, as one of the most energy-intensive sectors, is responsible for $16 \%$ of direct global $\mathrm{CO}_{2}$ emissions [5]. Without decisive action, energy-related $\mathrm{CO}_{2}$ emissions will keep increasing due to rapid development. For example, an annual average $\mathrm{CO}_{2}$ growth rate for the chemical industry is $3.37 \%$ in China during the 
period 1980-2010 [6]. Therefore, a low-carbon roadmap for the chemical industry is essential to make the right decisions for reducing $\mathrm{CO}_{2}$ emissions.

Given that the chemical industry is diverse and complex, the analysis has to be restricted to individual products [7]. Herein, ethylene is taken as an example because ethylene is one of the most important chemicals and its production process consumes $30 \%$ of the total energy of the chemical industry $[8,9]$. Ethylene can be used to produce polyethylene, polystyrene, polyethylene terephthalate and polyvinyl chloride [10]. In China, the ethylene industry has expanded dramatically from an annual production of 4.7 million metric tons in 2000 to 19.5 million metric tons in China in 2015 [11, 12]. However, a gap between supply and demand of ethylene still exists. Annual production of ethylene only reached $51.9 \%$ of the ethylene equivalent consumption in 2015 [12]. Therefore, the demand for ethylene will continue to show an increasing trend in the short term. To tackle high environmental impact and booming expansion associated with ethylene production site, the Chinese government and researchers have paid significant attention to upgrading and restructuring of ethylene plants $[13,14]$.

Ethylene is conventionally produced by steam cracking (SC), the feedstocks for which can be a broad range of hydrocarbon feedstocks [15]. Ethylene is predominantly from SC of mixed petroleum (PSC) in Europe and Asia, while North America and the Middle East adopt light hydrocarbons as feedstocks for SC $[7,15]$. This process is crucially dependent on petroleum and emits considerable $\mathrm{CO}_{2}$, which conflicts with the growing pressure for fossil fuel reduction and climate change mitigation. Therefore, alternative routes and feedstocks are explored and developed to adapt to the sustainable development of the olefins industry [15]. For example, China, with large coal reserves, focuses on the conversion of coal-based methanol-toolefins (CMTO) in an attempt to reduce reliance on imported petroleum [16]. By techno-economic analysis 
(TEA) and life cycle assessment (LCA), Xiang et al. [17] found that CMTO is economically competitive and independent of petroleum, however, controversies have accompanied this route because CMTO has a higher energy consumption and generates more greenhouse gas (GHG) emissions than the oil route [18, 19]. Furthermore, Chen et al. [20] found CMTO leads to about 2.5 times GHG emissions of PSC and NGbased methanol-to-olefins (NMTO), and the eco-efficiency of NMTO is the highest of the three production routes.

As an alternative to the route used in China, the U.S. has developed SC of natural gas liquids (NGLs) to ethylene due to its vast shale gas reserves. He et al. [21] conducted a techno-economic-environmental analysis of SC of shale gas (SSC) to olefin in the U.S. and found that shale regions of the U.S. could supply feedstocks for ethylene for more than 130 years. Besides, the comparison of SSC and SC of conventional natural gas (NSC) showed that the former has a little higher GHG emissions than the latter [8, 21].

SC and methanol-to-olefins (MTO) of natural gas, shale gas, and coal can reduce dependence on petroleum. However, these technologies still emit $\mathrm{CO}_{2} . \mathrm{CO}_{2}$ emissions in $\mathrm{CMTO}$ pathways are even higher than that of the PSC pathway. Carbon capture and storage (CCS) was used to reduce $\mathrm{CO}_{2}$ emissions. By LCA, Xiang et al. $[19,22]$ found that CMTO process with CCS is competitive in product cost despite low GHG emissions. However, the eco-efficiency of integration of CCS with CTO is lower than PSC and NMTO routes [20].

Switching from fossil sources to the renewable resources such as $\mathrm{CO}_{2}$ and biomass, particularly biowaste, is attractive since it can establish a sustainable and low carbon centre to produce chemicals [23, 24]. Some researchers have developed work associated with ethylene production adopting biomass as raw material. Hong et al. [9] performed an LCA to estimate corn- and cassava-based ethylene production. 
Liptow et al. [25] evaluated the environmental burden of biomass-based ethylene production routes via gasification and fermentation. Ghanta et al. [26] estimated environmental impacts of ethylene production from naphtha, ethane, and ethanol. This work focused on the environmental impacts of ethylene production, which makes a limited comparative analysis of $\mathrm{CO}_{2}$ or $\mathrm{GHG}$ emissions.

By LCA and TEA, the previous work assessed $\mathrm{CO}_{2}$ emissions of specific pathways for ethylene production. However, it is not appropriate to directly compare $\mathrm{CO}_{2}$ emissions among these pathways due to different system boundary, functional unit, location, allocation method and study time, as shown in Table 1. Given this, Ren et al. [27, 28] have made an extensive comparison of different olefins production routes in terms of energy use and $\mathrm{CO}_{2}$ emissions by a simplified method of LCA. Some processes, such as transportation are excluded in the study. Inaccuracy will be inevitable without regard to the uniform functional unit and appropriate system boundary. Also, some technologies, such as catalytic pyrolytic process (CPP), Fischer-Tropsch-to-olefins (FTO), MTO of $\mathrm{CO}_{2}$ have rarely been evaluated for energy consumption and $\mathrm{CO}_{2}$ emissions. Therefore, a comprehensive analysis of $\mathrm{CO}_{2}$ emissions of different pathways is imperative for guiding process development and promoting a $\mathrm{CO}_{2}$ emissions reduction in the ethylene industry.

Furthermore, with a rapid increase of annual ethylene production in China, work has also been devoted in the ethylene industry to reduce energy consumption and $\mathrm{CO}_{2}$ emissions. By replacing with the advanced equipment, implementing delicacy management, enlarging the scale of steam crackers, adjusting ratios of feedstocks and other technology, energy consumption has been reduced from $32.7 \mathrm{GJ} / \mathrm{t}$ ethylene in 2000 to 23.6 GJ/t ethylene in 2016 [13]. Energy consumption and $\mathrm{CO}_{2}$ emissions of ethylene production still have potential to reduce by optimizing production structure, replacing with advanced technology and attached 
technologies, such as air preheating technology of cracking furnace, enhanced heat transfer technology, etc.

[29]. However, few studies integrate this real-time change with a comparison of different pathways.

The focus of this study is to provide a comprehensive analysis of the life cycle $\mathrm{CO}_{2}$ emissions of different ethylene production pathways to tackle deteriorating climate change and rapid ethylene development. This study first describes and analyses alternative production approaches of ethylene, then provides a comparative LCA of the selected routes for evaluating $\mathrm{CO}_{2}$ emissions of each option. Scenario analysis is performed combining discussion of $\mathrm{CO}_{2}$ variation with technology, policy, and historical data, to identify the significant potential for reducing $\mathrm{CO}_{2}$ emissions, and a practical solution facing enormous demand of ethylene and pressure of climate change is proposed.

The study is structured as follows. A brief description of alternative production methods and system boundary of ethylene is presented in Section 2. Details of life cycle methodology and life cycle inventory are presented in Section 3. Section 4 describes the results of the carbon emissions of the model and the key findings of the study. Finally, we come to the conclusions in Section 5.

\section{Alternative production methods of ethylene}

Conventional production route is PSC. Alternative routes include SC of NGLs, CPP of heavy oil, MTO, syngas-to-olefins, and ethanol-to-ethylene (ETE). SC of NGLs can be sub-divided into conventional natural gas-base (NSC) and shale gas-base (SSC) based on the fact that two of the most abundant natural gas sources are shale gas (47.1\%) and conventional natural gas $(30.0 \%)$ in the U.S. in 2015 [30]. MTO route can be further sub-divided into four pathways according to feedstocks, i.e., coal (CMTO), natural gas (NMTO), $\mathrm{CO}_{2}(\mathrm{CO} 2 \mathrm{MTO})$ and biomass (BMTO). The syngas-to-olefins route is represented by a pathway of FTO, which can also be divided into four pathways according to raw resources. Herein, coal is taken as the example to study the FTO pathway (CFTO). The ten production pathways are shown in Fig. 1. 
Table 1 Variability in GHG emission results for different ethylene production pathways

\begin{tabular}{|c|c|c|c|c|c|c|c|}
\hline & Location & Study year & Functional unit & $\begin{array}{l}\text { Allocation } \\
\text { method }\end{array}$ & $\begin{array}{l}\text { Results } \\
\text { (t CO} 2 \text { eq/functional unit) }\end{array}$ & System boundary & Ref. \\
\hline \multirow[t]{3}{*}{ SC of mixed oil } & China & 2015 & t Olefins (ethylene, propylene) & - & $4-5$ & Oil extraction and processing, & [19] \\
\hline & China & 2017 & $\begin{array}{l}\text { t Olefins } \\
\text { (ethylene, propylene, butadiene) }\end{array}$ & Mass & 2.2 & $\begin{array}{l}\text { transportation, refining, } \\
\text { steam cracking }\end{array}$ & {$[20]$} \\
\hline & U.S.A. & 2014 & t Ethylene & Energy & 1.14 & & {$[26]$} \\
\hline \multirow[t]{2}{*}{ CMTO } & China & 2015 & t Olefins (ethylene, propylene) & - & 11.5 & Coal extraction and processing, & {$[19]$} \\
\hline & China & 2017 & $\begin{array}{l}\text { t Olefins } \\
\text { (ethylene, propylene, butadiene) }\end{array}$ & Mass & 5.3 & $\begin{array}{l}\text { transportation, gasification, } \\
\text { methanol synthesis, (CCS,) MTO }\end{array}$ & {$[20]$} \\
\hline CMTOwCCS & China & 2015 & t Olefins (ethylene, propylene) & - & $7-8$ & & {$[19]$} \\
\hline \multirow[t]{2}{*}{ NGMTO } & China & 2015 & t Olefins (ethylene, propylene) & - & $4-5$ & NG extraction and processing, & {$[19]$} \\
\hline & China & 2017 & $\begin{array}{l}\text { t Olefins } \\
\text { (ethylene, propylene, butadiene) }\end{array}$ & Mass & 2.1 & transportation, methanol synthesis, MTO & {$[20]$} \\
\hline \multirow[t]{2}{*}{ NGSC } & U.S.A. & 2015 & t HVC & - & $1.8-2.2$ & NG recovery, NG processing, & {$[8]$} \\
\hline & U.S.A. & 2014 & t Ethylene & Energy & 0.84 & transportation, ethylene production & {$[26]$} \\
\hline \multirow[t]{3}{*}{ SGSC } & U.S.A. & 2015 & t HVC & - & $2.0-3.4$ & SG recovery, SG processing, & {$[8]$} \\
\hline & U.S.A. & 2016 & t Ethylene & Mass & $0.75-1.05$ & transportation, ethylene production & {$[21]$} \\
\hline & U.S.A. & 2016 & t Ethylene & Economic & $1.24-2.13$ & & {$[21]$} \\
\hline Corn-based ETE & China & 2014 & t Ethylene & Mass & $2.7-4.1$ & $\begin{array}{l}\text { Corn production, transportation, } \\
\text { ethanol production, ETE, waste treatment }\end{array}$ & {$[9]$} \\
\hline Cassava-based ETE & China & 2014 & t Ethylene & Mass & $4.3-7.4$ & $\begin{array}{l}\text { Cassava production, transportation, } \\
\text { ethanol production, ETE, waste treatment }\end{array}$ & {$[9]$} \\
\hline Wood-based MTO & Sweden & 2015 & t Ethylene & Economic & $0.28-0.3$ & $\begin{array}{l}\text { Biomass acquisition, transportation, } \\
\text { gasification, methanol synthesis, MTO }\end{array}$ & {$[25]$} \\
\hline \multirow[t]{2}{*}{ Wood-based ETE } & Sweden & 2013 & t Ethylene & - & $5.2-5.6$ & Biomass acquisition, transportation, & {$[31]$} \\
\hline & Sweden & 2013 & t Ethylene & - & $3.2-3.6$ & $\begin{array}{l}\text { ethanol production, enzyme production, } \\
\text { ETE }\end{array}$ & [31] \\
\hline
\end{tabular}

* - means no allocation method 
The method adopted in this study is life cycle assessment (LCA), which is defined as the "compilation and evaluation of the inputs, outputs and potential environmental impacts of a product system throughout its life cycle" by ISO $14040[32,33]$. The functional unit is defined as one metric ton (t) of ethylene.

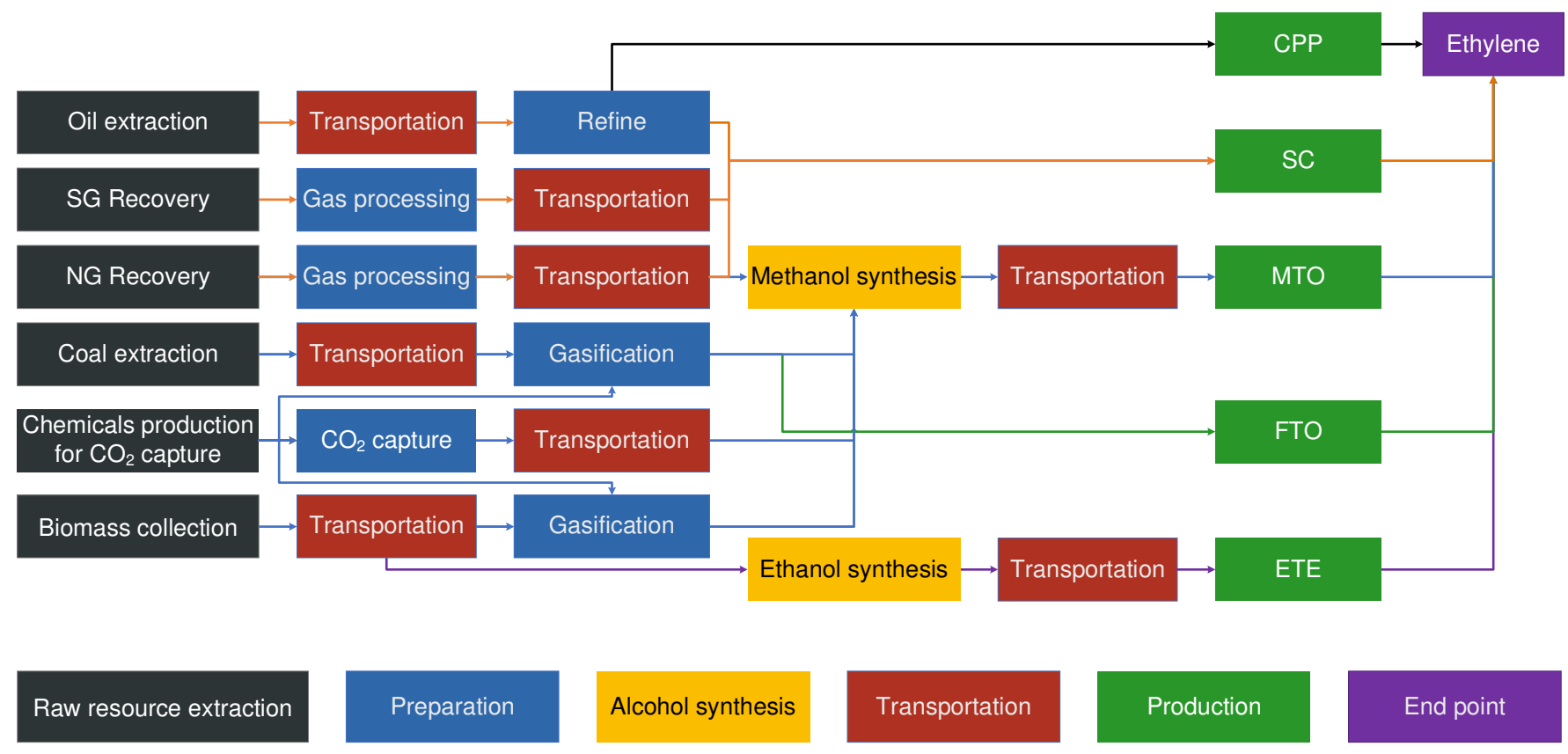

Fig. 1. The system boundary of different pathways of ethylene production.

\subsection{System boundary}

Five routes including ten alternative pathways have been investigated. Life cycle assessment requires input-oriented units of all processes and each pathway consists of a series of processes [34, 35]. Therefore, an appropriate system boundary is of great importance. In this study, all life cycle assessment criterion for ethylene production via different pathways has been considered, excluding the impacts of plant construction and equipment maintenance due to the long lifetime associated with infrastructure. Detailed tracking of each pathway is obtained, including raw resources or materials, all products, all type of energy and $\mathrm{CO}_{2}$ emissions [36]. Energy type includes coal, diesel, gasoline, residual oil, natural gas, steam, and electricity. 
The system boundary is depicted in Fig. 1, and the five routes are emphasized by different colour linkages.

Briefly, the PSC pathway includes four discrete unit operations. The four different stages are raw oil extraction, transportation, oil refining and steam cracking. Similar to PSC pathway, CPP pathway consists of a catalytic pyrolytic process following oil refining. NSC and SSC pathways are composed of recovery of natural gas and shale gas, processing of natural gas and shale gas, transportation and steam cracking process. CMTO, NMTO, CO2MTO and BMTO pathways include a methanol-to-olefins process following the methanol synthesis from natural gas, coal, $\mathrm{CO}_{2}$, and biomass. The upper stream of methanol in NMTO pathway is similar to that in the NSC pathway, while it consists of coal extraction and gasification process in the CMTO pathway. Meanwhile, syngas from coal gasification can be directly converted into olefins via Fischer-Tropsch synthesis (CFTO pathway). Upstream of CO2MTO pathway includes chemicals production for $\mathrm{CO}_{2}$ capture and $\mathrm{CO}_{2}$ capture before methanol synthesis. Straw, as the model of biomass in this study, is started from biomass collection rather than biomass production because straw is traditionally used as an agricultural waste burned by Chinese farmers after harvest [37]. After transportation, biomass undergoes a gasification process before methanol synthesis or transforms into ethanol via a fermentation process. Ethanol is then dehydrated into ethylene (BETE pathway).

\subsection{Life cycle inventory data}

$\mathrm{CO}_{2}$ emissions arising from the integrating stage of extraction and transportation of fossil resources are obtained from literature [38]. Other relevant processes are determined by using primary data representing production in 2013. $\mathrm{CO}_{2}$ emissions arising from each process can be counted as the sum of process emissions, fuel emissions and indirect emissions [39]. Process emissions are calculated according to the carbon content of feedstocks and products. The fuel emissions are calculated by multiplying the activity 
data (e.g., amounts of fuels burned) with carbon content factor and oxidation rate of the activity data.

Indirect emissions are calculated by multiplying the activity data with an emission factor (e.g., amount of $\mathrm{CO}_{2}$ per unit fuel production) [39-44].

Various factors are taken from literature [40-43], whereas estimation of the fuels consumed in each process is developed from an extensive literature survey, industry data, statistical yearbooks, site investigation and process simulation. Detailed data collection can be found in the following sections, which gives a summary of each pathway.

\section{Inventory analysis of each pathway}

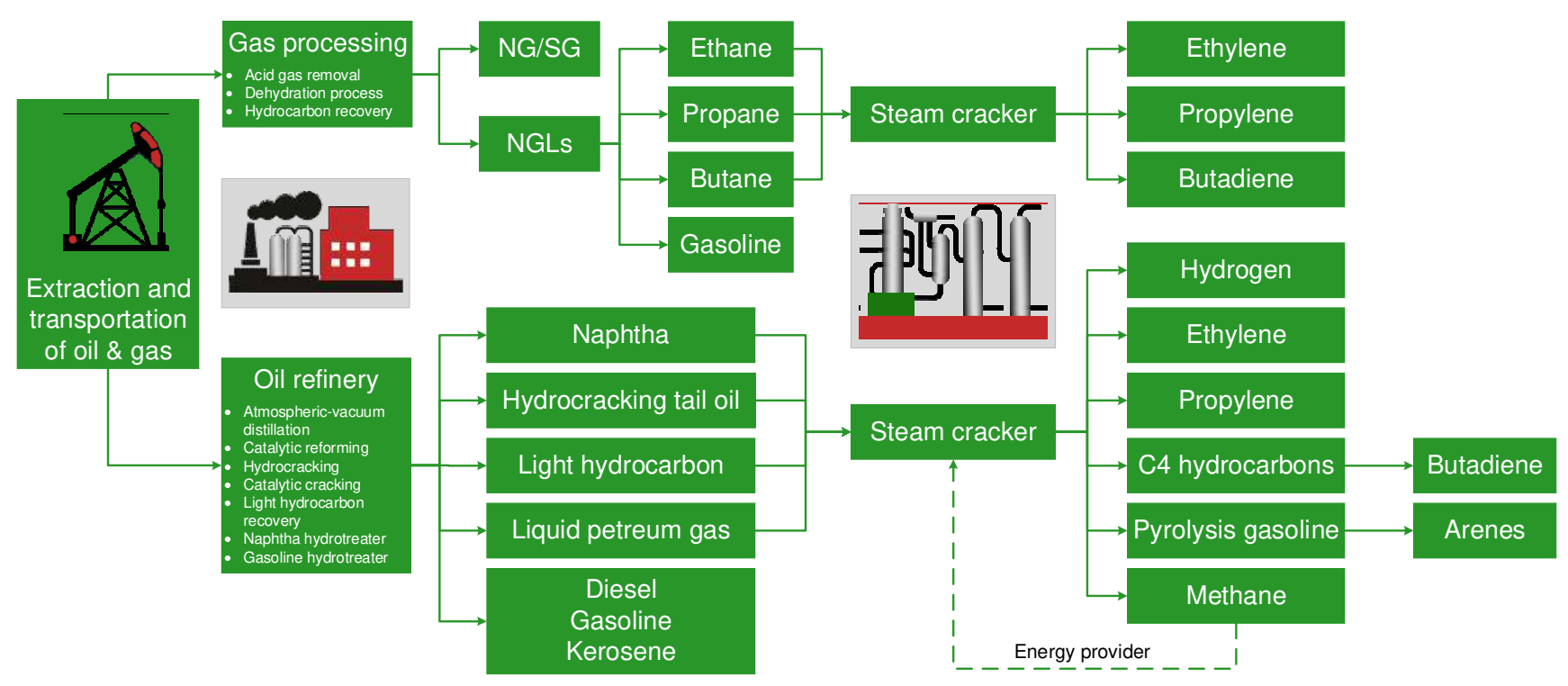

Fig. 2. Process for producing ethylene from steam cracking of two different feedstocks.

\subsection{Steam cracking of mixed petroleum and natural gas liquids}

Steam cracking produces a variety of products, such as ethylene, propylene, and aromatics. The feedstocks of steam cracking range from light hydrocarbons (ethane, propane, and butane) to petroleum 
liquids (naphtha and distillate fuel oil) [7]. Statistics show that global steam cracking of petroleum liquids and light hydrocarbons accounted for about $45.0 \%$ and $49.0 \%$ of ethylene production in 2015 , respectively [45]. Products differ with the change of feedstocks and operating conditions, as shown in Fig. 2. More byproducts are obtained from steam cracking of petroleum liquids than that of light hydrocarbons.

\subsubsection{Steam cracking of mixed petroleum (PSC)}

As described in previous work [39], naphtha, hydrocracking tail oil, light hydrocarbons, liquid petroleum gas and raffinate oil are converted into ethylene and by-products via SC in China. The byproducts include methane, hydrogen, propylene, C4 hydrocarbons and pyrolysis gasoline, among which C4 hydrocarbons and pyrolysis gasoline are used to produce butadiene and arenes. Ethylene, propylene, butadiene, hydrogen, and arenes are high-value chemicals (HVCs) in this process and take part in mass allocation. The yield of HVCs is $60.7 \%$ [46]. The energy input for the process is $22.7 \mathrm{GJ} / \mathrm{t}$ ethylene and energy consists of $79.3 \%$ methane, $3.1 \%$ electricity and others [47]. The refining process involves seven units: atmospheric-vacuum distillation, catalytic reforming, hydrocracking, catalytic cracking, light hydrocarbon recovery, naphtha hydrotreater and gasoline hydrotreater. The inventory of the refining process has been described in previous work [39].

Additionally, a variety of life cycle $\mathrm{CO}_{2}$ emissions for petro-ethylene production from 2000 to 2016 are calculated in section 4.2 .

\subsubsection{Steam cracking of natural gas liquids (NSC and SSC)}

Due to abundant reserves of methane-rich natural gas and shale gas, ethylene is produced predominantly by steam cracking of NGLs in the U.S. [8]. Raw conventional natural gas or shale gas is first scrubbed to remove contaminants such as $\mathrm{CO}_{2}, \mathrm{H}_{2} \mathrm{~S}$, and $\mathrm{N}_{2}$, and then a gas-liquid separation process 
is performed. The gas is natural gas (NG), mostly consisting of methane, and the liquid is NGLs, which consist primarily of ethane, propane, iso-butane, $n$-butane and other hydrocarbons [21, 48, 49]. Ethylene can be obtained from NGLs via the process of steam cracking.

Given that NSC and SSC are just emerging in China, limited data can be obtained. Herein, previous U.S. LCA studies of NSC and SSC are referred [8]. By a localizing revise, we obtain the life cycle $\mathrm{CO}_{2}$ emissions of NSC and SSC.

\subsection{Catalytic pyrolytic process of heavy oil (CPP)}

CPP technology, adopting paraffin-based atmospheric residue as feedstock, has been developed due to the shortage of light feedstocks for steam cracking in China. It was put into commercial operation in China in 2009 [50]. A CPP model consists of the CPP system, an ethane-propane tubular cracking furnace, and the pyrolysis gas purification and separation system. Atmospheric residue undergoes catalytic and thermal cracking reactions in the reactor of the CPP system. The generated products are rapidly cooled and separated into cracked gas, naphtha and cat-cracking light oil fractions. The cracked pyrolysis gas is further separated into ethylene, propylene, ethane, propane and $\mathrm{C} 4$ fraction. The ethane and propane are further routed to the tubular cracking furnace and crack into ethylene and propylene [51]. According to previous work [52], 6.1 $\mathrm{t}$ atmospheric residues and 22.2 GJ energy are put into the CPP system, which generates $1.0 \mathrm{t}$ ethylene and $4.6 \mathrm{t}$ other products.

From the view of LCA, the atmospheric residue is obtained from atmospheric distillation. Atmospheric distillation is a unit of the refining process, which consumes $5.4 \mathrm{t}$ crude oil and $4.8 \mathrm{GJ}$ energy to produce $1.0 \mathrm{t}$ atmospheric residue coupled with $4.3 \mathrm{t}$ other by-products, such as wax oil and virgin naphtha [39]. 


\subsection{Methanol-to-olefin route}

Motivated by the increasing demand for ethylene and the shortage of petroleum, China focuses on the conversion of coal-based syngas or methanol to olefins because of its large coal reserves [16, 53]. The industrial production of methanol is mainly from syngas, which is traditionally produced from fossil fuels [54]. These processes operated at high reaction temperature and high pressure have serious impacts on the environment. Syngas consists of $\mathrm{CO}, \mathrm{H}_{2}$ and small traces of $\mathrm{CO}_{2}$. New pathways have been attempted to produce methanol by adopting $\mathrm{CO}_{2}$ and biomass, which can effectively reduce or avoid $\mathrm{CO}_{2}$ emissions, as shown in Fig. 3 [54-66]. However, a commercial plant adopting non-fossil fuels has not been built so far. Conversion of four resources into methanol is summarized in the following sections and data sources of MTO are described at last.

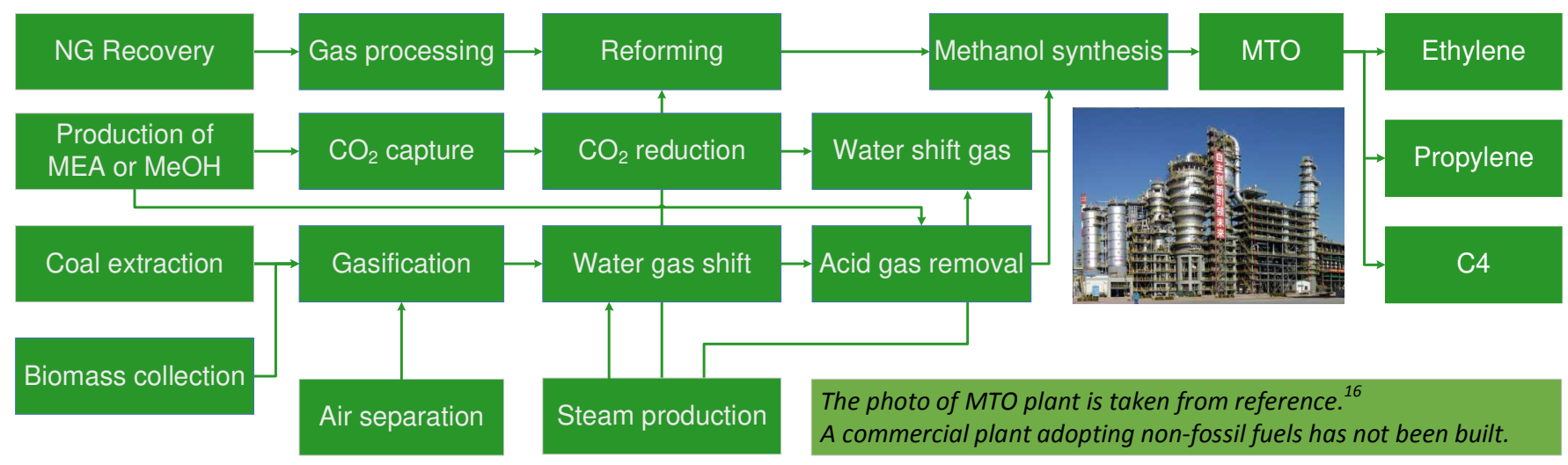

Fig. 3. Processes for producing ethylene from methanol originating from four different resources.

\subsubsection{Coal to methanol}

The CMTO model mainly consists of three parts: coal gasification (CG), methanol synthesis (MS) and MTO unit. Other units including air separation unit (AS), water gas shift unit (WGS) and acid gas removal 
unit (AGR) are also essential modules in CMTO plant.

A detailed production process of coal to methanol has been simulated using Aspen Plus software (details can be found in Section A.1 in the Appendix Material) [22, 67, 68], which covers AS unit, CG unit, WGS unit, AGR unit, MS unit, and methanol purification unit. For brevity, AS unit, CG unit, WGS unit, and AGR unit are categorised into CG process, while MS unit and methanol purification unit are categorised into the methanol synthesis process. The results show that $1.4 \mathrm{t}$ coal is consumed to produce $1.0 \mathrm{t}$ methanol. The energy consumptions are 2.9 GJ and 0.4 GJ in the coal gasification process and methanol synthesis process, respectively. It is noted that the Rectisol method is used in the AGR unit because of its widespread application in coal-based chemical processes [69]. It can remove $\mathrm{H}_{2} \mathrm{~S}, \mathrm{COS}$, and $\mathrm{CO}_{2}$. The Rectisol method is easy to connect with the $\mathrm{CO}_{2}$ storage system. Further discussion can be found in section 4.3.

\subsubsection{Natural gas to methanol}

Methanol is produced traditionally from NG in regions with large NG reserves [70]. As described in section 3.1.2, NG is obtained after NG recovery and processing. NG is transformed into syngas with steam and small amounts of $\mathrm{CO}_{2}$ at high temperature in the reforming process. Then methanol is synthesized from syngas. According to previous literature [57, 70], $0.7 \mathrm{t} \mathrm{NG}, 0.1 \mathrm{t}$ water in conjunction with 1.9 GJ energy are utilised per tonne of methanol production.

\subsection{3. $\mathrm{CO}_{2}$ to methanol}

Conversion of $\mathrm{CO}_{2}$ into methanol primarily consists of $\mathrm{CO}_{2}$ capture and methanol synthesis. There are a number of technologies [71] that can achieve $\mathrm{CO} 2$ capture. Herein, monoethanolamine (MEA) scrubbing process is adopted, which is a promising technology for post-combustion capture of $\mathrm{CO}_{2}$ [72]. A flow of waste gas with a high concentration of $\mathrm{CO}_{2}$ is assumed without considering the $\mathrm{CO}_{2}$ source. About $90 \%$ of 
$\mathrm{CO}_{2}$ can be removed, and it will consume $370-413 \mathrm{~kW} \cdot \mathrm{h}$ of electricity per $\mathrm{CO}_{2}[58,72,73]$. Meanwhile, about $1.5 \mathrm{~kg} \mathrm{MEA} / \mathrm{t}$ captured $\mathrm{CO}_{2}$ is required to make up because of the degradation and loss of MEA. Production inventory of MEA is taken from literature [73]. Then $\mathrm{CO}_{2}$ is compressed and transported to plant to be converted into methanol. Transportation is assumed to be via pipeline, and the distance is set at $300 \mathrm{~km}$, which will consume $111.6 \mathrm{~kW} \cdot \mathrm{h}$ electricity per t $\mathrm{CO}_{2}[58,73,74]$.

Synthesis strategies of biochemical, electrochemical, thermochemical and photochemical are attempted to transform $\mathrm{CO}_{2}$ into methanol [57, 75-77]. Photocatalytic conversion of $\mathrm{CO}_{2}$ and water to methanol is investigated because it can achieve a net reduction in $\mathrm{CO}_{2}[57,58] . \mathrm{CO}_{2}$ is first transformed into $\mathrm{CO}$ and $\mathrm{O}_{2}$ over metal oxide, and a water gas shift reaction subsequently adjusts the $\mathrm{H}_{2} / \mathrm{CO}$-ratio to attain the maximum yield of methanol [57]. Methanol is then separated from a mixture of water and methanol. It consumes $1.5 \mathrm{t} \mathrm{CO}_{2}, 1.3 \mathrm{t} \mathrm{H}_{2} \mathrm{O}$, and $1.6 \times 10^{3} \mathrm{~kW} \cdot \mathrm{h}$ energy when $1 \mathrm{t}$ methanol is produced in the photocatalytic reactor [58].

\subsubsection{Biomass to methanol}

From biomass to methanol, the processes are composed of chemicals production of biomass cultivation, biomass extraction, transportation, pre-treatment, gasification, and methanol synthesis. Biomass extraction is an agricultural process which involves several steps - cultivation, fertilizing, harvesting, collection, and transportation [56]. Pre-treatment involves drying and crushing, achieving an optimal material moisture content and particle size for gasification.

As described in section 2.1, straw is taken as the example of a biomass feedstock because about 870 million metric tons of straw is produced every year in China [78]. Chemicals production of biomass cultivation and biomass extraction have been excluded out of LCA. Straw is collected, transported and pre- 
treated followed by gasification. Straw is transported to $20 \mathrm{~km}$ by diesel vehicle based on a previous statistics [79], and $71.9 \mathrm{~kW} \cdot \mathrm{h}$ electricity is consumed in the processes of collection and pre-treatment [37].

Similar to coal to methanol, biomass to methanol (including gasification and methanol synthesis) is simulated using Aspen Plus software [80-83], and details can be found in Section A.2 in the Appendix material. The results of the simulation show that $2.5 \mathrm{t}$ anhydrous straw is consumed per $\mathrm{t}$ methanol production accompanied by $3.5 \mathrm{t} \mathrm{CO}_{2}$ emissions. Energy requirements are $3.7 \mathrm{GJ}$ and $0.3 \mathrm{GJ}$ in straw gasification process and methanol synthesis process, respectively.

\subsubsection{Methanol-to-olefins (MTO)}

MTO reaction is a critical stage that connects non-petroleum resources with basic petrochemicals. It is carried out over different types of zeolites or molecular sieves, typically ZSM-5, SAPO-34 and MOR [84].

In the present work, the inventory is based on the Dalian Institute of Chemical Physics' MTO (DMTO) technology. According to previous literature $[85,86], 1.0 \mathrm{t}$ methanol with 10.7 GJ energy can be converted into $0.2 \mathrm{t}$ ethylene, $0.2 \mathrm{t}$ propylene, and $0.1 \mathrm{t} \mathrm{C4}$ hydrocarbons. In addition, from a view of LCA, a $100 \mathrm{~km}$ transportation of methanol by diesel vehicle is assumed.

\subsection{Fischer-Tropsch to olefins pathway (CFTO)}

The processes of converting syngas into light olefins can be divided into indirect and direct conversion. MTO is an example of the former, and the latter is represented by FTO [87]. FTO is transforming syngas into hydrocarbons and alcohols has been studied for more than 50 years [15]. A variety of studies optimizing reaction condition have been reported, and many metal catalysts, such as iron, cobalt, nickel, and ruthenium have been tested $[15,88-90]$. However, application of this technology is still limited due to low olefin selectivity, high methane selectivity, and severe carbon deposition. Besides FTO, Jiao et al. [91] developed 
a bifunctional catalyst to convert syngas into olefins directly.

FTO pathway mainly consists of gasification and Fischer-Tropsch synthesis. Furthermore, gasification is split into AS unit, CG unit, and AGR unit, and Fischer-Tropsch synthesis contains FTO unit and olefins separation unit. Similar to Section 3.3, the raw material can be coal, $\mathrm{NG}, \mathrm{CO}_{2}$, and biomass. Herein, coal is taken as the example, and coal-to-olefins is simulated using Aspen Plus software (details can be found in Section A.3 in the Appendix material) based on previous literature with some modification [10, 67].

The results of the simulation show that $1.0 \mathrm{t}$ coal can be transformed into $0.14 \mathrm{t}$ HVCs. Products distribution of HVCs includes $32.1 \%$ of ethylene, $49.1 \%$ of propylene and $18.8 \%$ of 1-butene. Energy input is $2.3 \mathrm{GJ}$ and $3.2 \mathrm{GJ}$ in $\mathrm{CG}$ and FTO process, respectively. It is noted that the olefins separation unit in the FTO process requires a $\mathrm{CO}_{2}$ removal unit because nearly $30 \%$ of $\mathrm{CO}$ is converted into $\mathrm{CO}_{2}$. The $\mathrm{CO}_{2}$ removal is achieved by the MEA scrubbing. Both of the processes of $\mathrm{CG}$ and FTO release $0.6 \mathrm{t} \mathrm{CO}_{2}$.

\subsection{Ethanol-to-ethylene route (BETE)}

Besides MTO and FTO routes, biomass can be transformed into ethylene by using ethanol as an intermediate [92, 93]. Bio-ethanol can be obtained from different renewable materials via different industrial processes which include fermentation and gasification. Conversion from sugar- or starch-rich biomass crops such as corn and sugarcane can be achieved by processes of fermentation and distillation. If using lignocellulose materials like wood and sugarcane bagasse as feedstock, the ethanol can be achieved by processes of pre-treatment, enzymatic hydrolysis, fermentation, and distillation. Ethanol can be produced from algal biomass by processes including pre-treatment, saccharification, fermentation, and distillation or membrane technology. The different methodologies and feedstocks are categorised into socalled "first-, second- and third-generation" bioethanol, as depicted in Fig. 4 [94-97]. Transformation of 
ethanol into ethylene occurs through ethanol dehydration under the conditions of appropriate temperature and catalyst $[92,93]$. Similar to section 3.3 .4 , straw is taken as a biomass resource because it avoids competition with human food. A detailed LCA of BETE with straw as the feedstock is composed of biomass transportation, pre-treatment, fermentation to ethanol, and ethanol to ethylene.

As described by Hong et al. [37], $7.5 \mathrm{t}$ straw can be converted into $1.0 \mathrm{t}$ ethanol and $0.6 \mathrm{t}$ dried grains. Meanwhile, $12.4 \mathrm{t}$ sewage with an average BOD concentration of $55.0 \mathrm{~kg} / \mathrm{m}^{3}$ is produced. Electricity consumption is $1.3 \mathrm{~kW} \cdot \mathrm{h} / \mathrm{kg}$-BOD treatment [98]. It consumes $1.7 \mathrm{t}$ ethanol, $370 \times 10^{3} \mathrm{~kW} \cdot \mathrm{h}$ electricity, and $0.1 \mathrm{t}$ residual oil when $1.0 \mathrm{t}$ ethylene is transformed. The transportation distance is assumed to be $100 \mathrm{~km}$ by diesel vehicle.

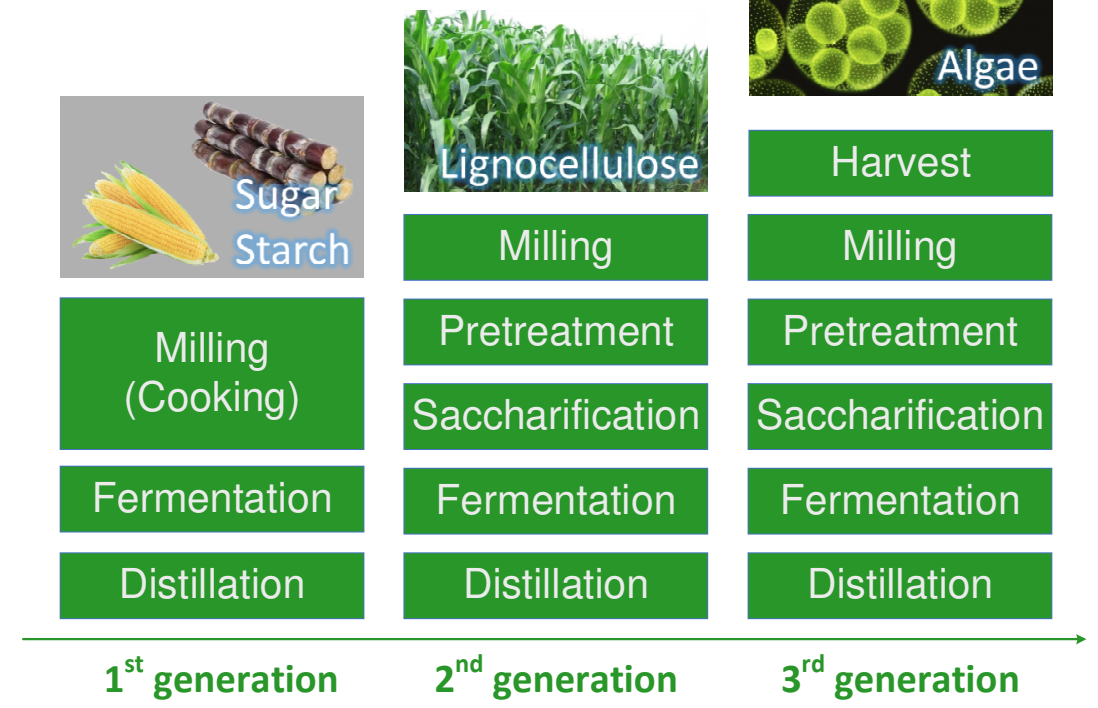

Fig. 4. Materials and processes of three generations of bioethanol production. 


\section{Results and discussion}

\subsection{Life cycle $\mathrm{CO}_{2}$ emissions of different production pathways for ethylene}

The inventory of ethylene production via ten pathways has been obtained as above, and the results are shown in Fig. 5. PSC pathway releases $1.7 \mathrm{t} \mathrm{CO}_{2}$ per t ethylene production, which is taken as the evaluation criteria due to its dominant role (98.5\% of total ethylene production in 2014) in the ethylene industry in China. NSC and SSC pathways reduce $\mathrm{CO}_{2}$ by $0.4 \mathrm{t}$ and $0.3 \mathrm{t}$, respectively. CPP releases more $\mathrm{CO}_{2}$ by 1.6 $\mathrm{t}$ than PSC pathway does, which is more than two times of that arising from NSC and SSC. MTO route represents a wide range of $\mathrm{CO}_{2}$ emissions. $\mathrm{CO} 2 \mathrm{MTO}$ pathway presents negative $\mathrm{CO}_{2}$ emissions because the carbon in ethylene is obtained from $\mathrm{CO}_{2}$. The carbon is fixed in chemicals, which means the carbon sink. BMTO pathway releases $2.2 \mathrm{t} \mathrm{CO}_{2}$ per t ethylene production, which is more than that of PSC pathway. In order to explore the potential of the carbon emissions mitigation, CCS was integrated into BMTO pathway. $\mathrm{CO}_{2}$ emissions were reduced to $-6.0 \mathrm{t}$ via $\mathrm{BMTO}$ with $\mathrm{CCS}$, which present a considerable potential for carbon emission reduction. $\mathrm{CO}_{2}$ arising in NMTO is almost twice as much as that of PSC. CMTO releases $11.6 \mathrm{t} \mathrm{CO}_{2} / \mathrm{t}$ ethylene, which is the second most $\mathrm{CO}_{2}$ emitter. The highest $\mathrm{CO}_{2}$ emission pathway is CFTO, which releases $18.4 \mathrm{t} \mathrm{CO}_{2} / \mathrm{t}$ ethylene. CCS can help CMTO and CFTO reduce $\mathrm{CO}_{2}$ by $40.7 \%$ and $33.7 \%$. However, both of them still release more $\mathrm{CO}_{2}$ than that of other pathways. BETE pathway possesses a slightly lower $\mathrm{CO}_{2}$ emission than NSC pathway does. 


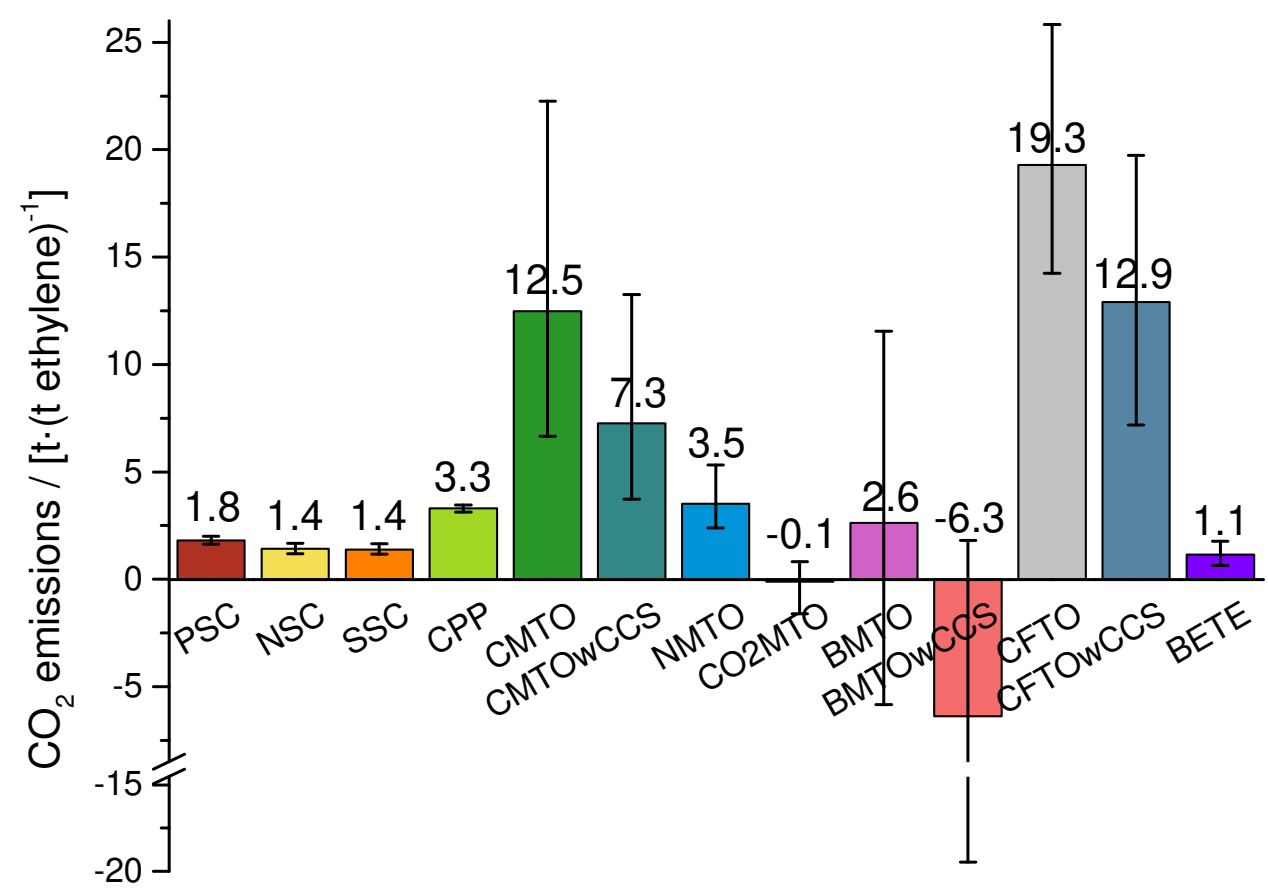

Fig. 5. $\mathrm{CO}_{2}$ emissions from different pathways of ethylene production.

From the viewpoint of raw resources, the non-fossil pathways including CO2MTO, BMTO, and BETE have better potentials in $\mathrm{CO}_{2}$ emission reduction than fossil resources. For three fossil resources, i.e., petroleum, natural gas and coal, coal pathways including CMTO and CFTO release more $\mathrm{CO}_{2}$ than others. For petroleum and natural gas, SSC and NSC release less $\mathrm{CO}_{2}$ than that of other fossil pathways, while PSC and $\mathrm{CPP}$ release less $\mathrm{CO}_{2}$ than that of NMTO. $\mathrm{CO}_{2}$ emissions via the CMTO pathway and CFTO pathway are much more than other pathways. 


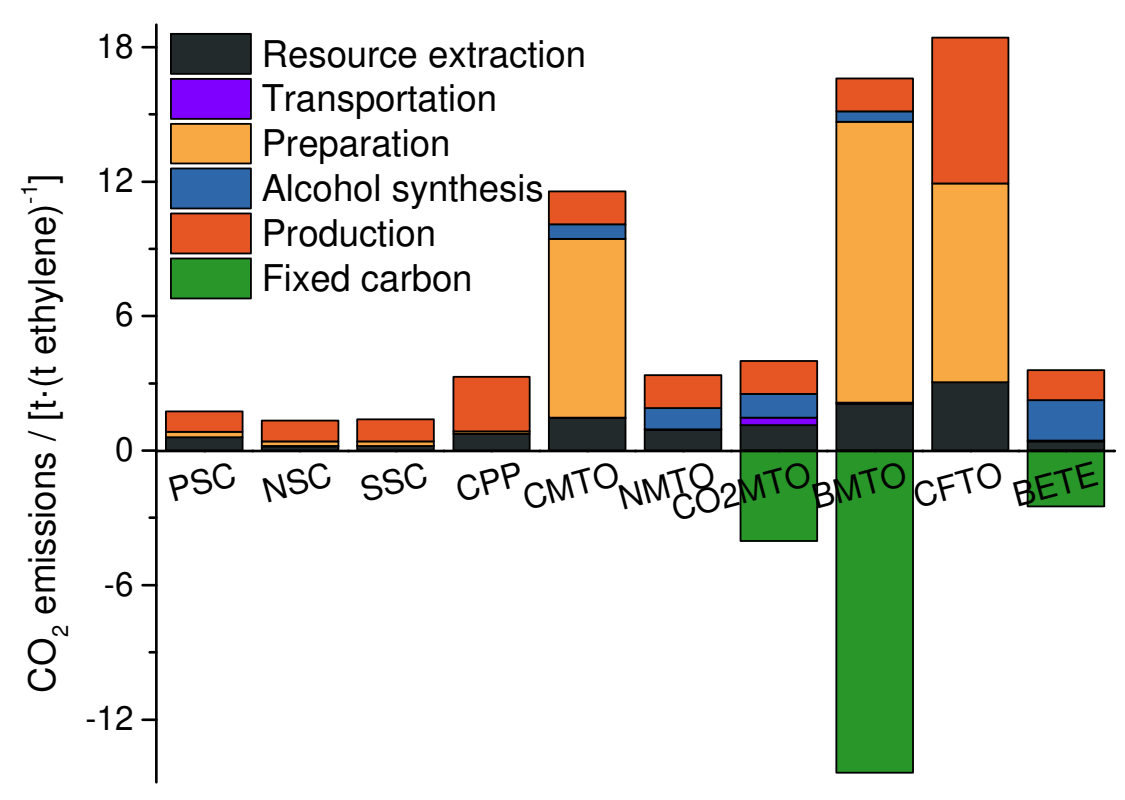

Fig. 6. $\mathrm{CO}_{2}$ emissions from different stages of ethylene production via different pathways.

The individual contribution of each stage of the life cycle of ethylene production is shown in Fig. 6. The fixed carbon represents the carbon content of the chemicals coming from the atmosphere rather than from fossil resources. Therefore, it presents a negative number in the figure. It can be seen that the most $\mathrm{CO}_{2}$ emission process is gasification process (preparation stage), which releases $8.0 \mathrm{t}, 12.5 \mathrm{t}$ and $8.9 \mathrm{t} \mathrm{CO}_{2}$ per ethylene production in pathways of CMTO, CFTO, and BMTO, respectively. Meanwhile, FTO process (production stage in CFTO pathway) is also responsible for $35.3 \% \mathrm{CO}_{2}$ in CFTO pathway. Both the gasification and FTO process are the critical technologies for reducing $\mathrm{CO}_{2}$ emissions in the life cycle of ethylene production. The strategy of carbon capture and storage can be used to decrease $\mathrm{CO}_{2}$ emissions, which is discussed in section 4.3. The process of MTO releases $1.5 \mathrm{t} \mathrm{CO}_{2}$ per $\mathrm{t}$ ethylene, which plays an essential role in four MTO pathways. Resource extraction and methanol synthesis also play essential roles in the MTO pathway. Note that transportation contributes $8.3 \% \mathrm{CO}_{2}$ to $\mathrm{CO} 2 \mathrm{MTO}$ pathways, while it plays a negligible role in other pathways. In the pathway of BETE, ethanol synthesis process contributes the most 
$\mathrm{CO}_{2}$ emissions (50.3\%). The ETE process (production stage in BETE pathway) also plays an important role. In PSC, NSC and SSC pathway, the steam cracking process contributes more than $51.6 \% \mathrm{CO}_{2}$ in the life cycle of ethylene production.

\subsection{Energy-saving measure on ethylene production with years}
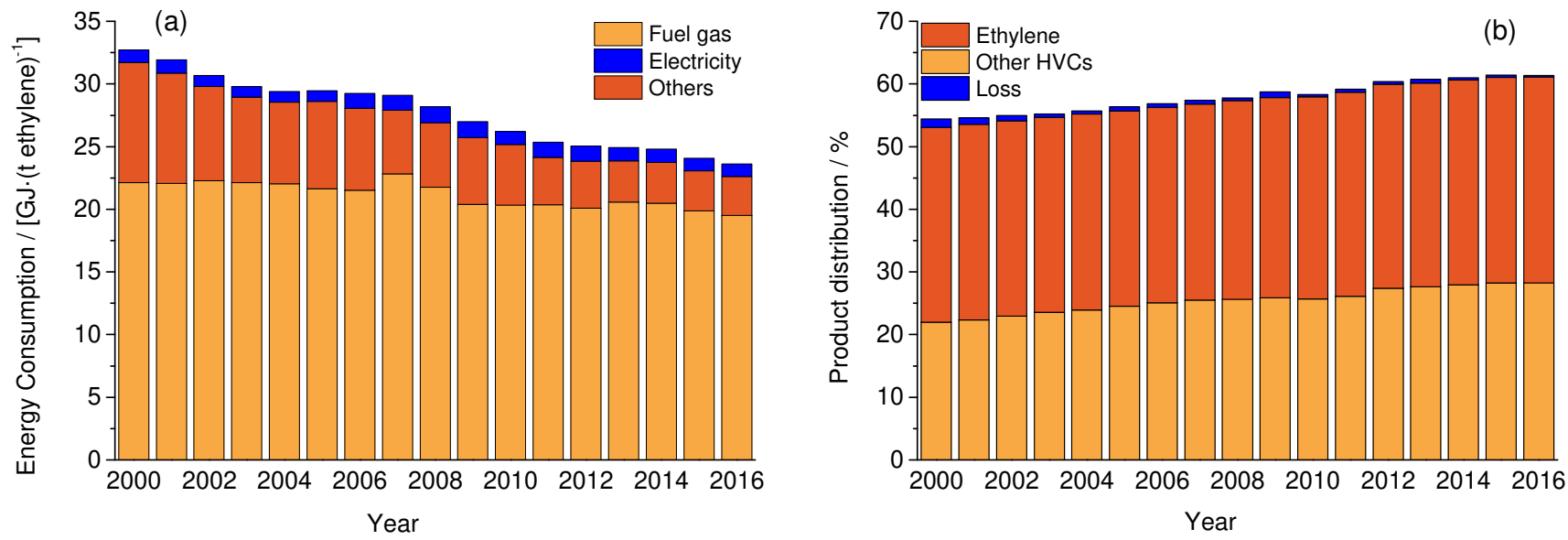

Fig. 7. Inventory data on petro-ethylene production from 2000 to 2016: (a) energy consumption, (b)

product distribution.

Developing more efficient strategies that are capable of reducing $\mathrm{CO}_{2}$ emissions in converting fossil resources into fuels and chemicals has been a concern by a variety of industries since the eleventh five-year plan issued in China [99]. By replacing with advanced equipment, implementing delicacy management, enlarging the scale of steam crackers, adjusting ratios of feedstocks and other technology, $\mathrm{CO}_{2}$ emissions have been sharply reduced in the ethylene industry [13]. Life cycle $\mathrm{CO}_{2}$ emissions of ethylene within the last seventeen years have been based on a simplified feedstock form due to the limited data available. In this study, ethylene yield, HVCs yield, loss ratio, recycle oil ratio, energy consumption including fuel gas, electricity and other energy forms of petro-ethylene production have been collected, as shown in Fig. 7. 
$\mathrm{CO}_{2}$ emissions of primary energy are taken from literature [38], and temporal correlation has not been considered due to limited inventory data. More details can be found in Section A.4 in the Appendix material.

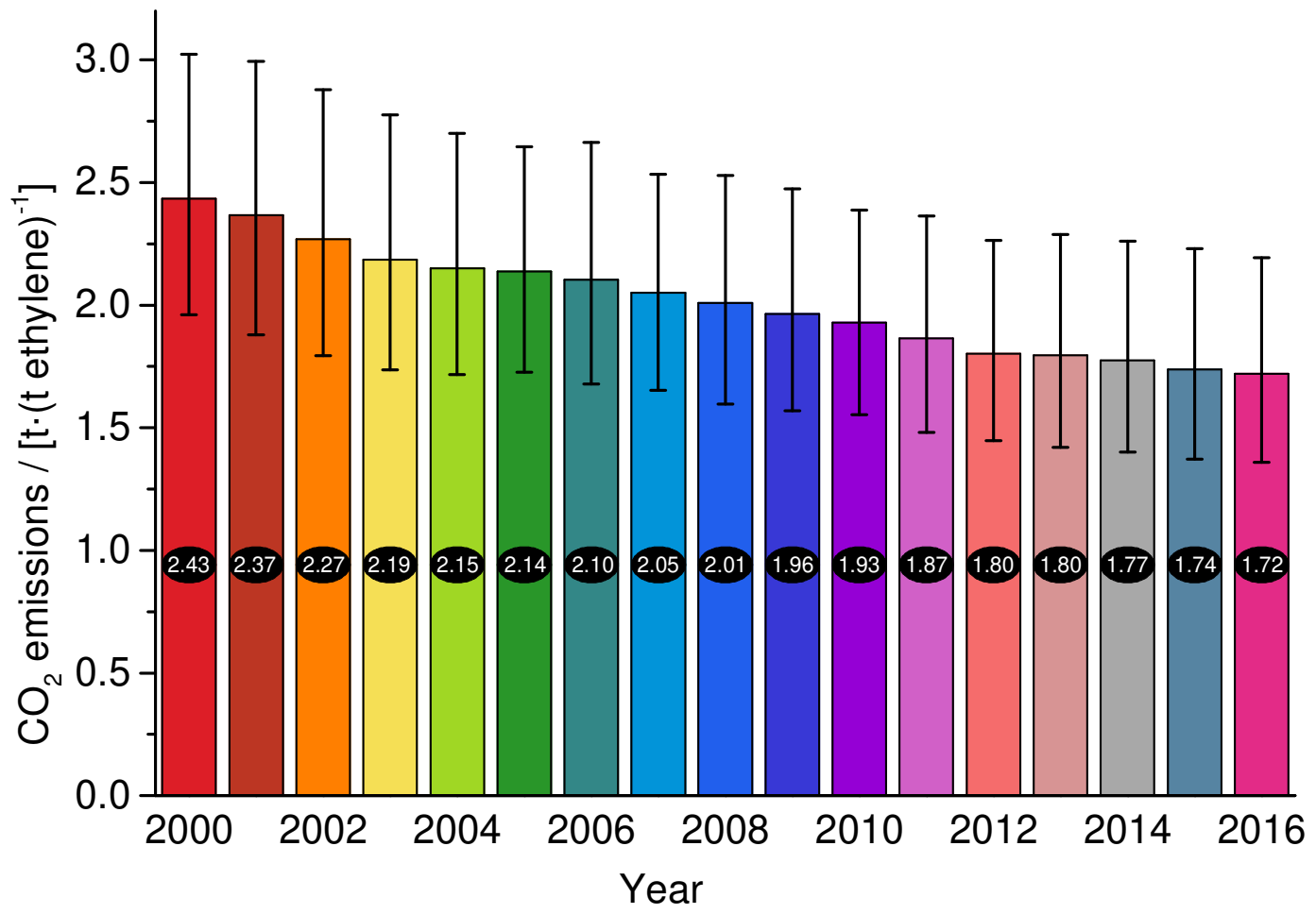

Fig. 8. $\mathrm{CO}_{2}$ emissions of petro-ethylene production from 2000 to 2016.

The results in Fig. 8 show that $\mathrm{CO}_{2}$ emissions from ethylene production have been declining in China. The reason is declining energy consumption and loss ratio as well as the increasing trend of HVCs yield. The $\mathrm{CO}_{2}$ emissions per unit ethylene production have decreased by $29.4 \%$ in spite of the fact that temporal correlation of primary energy has been not considered, while the yield of ethylene has increased from $31.1 \%$ in 2000 to $32.8 \%$ in 2016 , indicating the improved efficiencies. 


\subsection{Comparison of carbon capture and storage (CCS)}

Developing more efficient conversion pathways for fossil resources can reduce energy consumption and $\mathrm{CO}_{2}$ emissions, while CCS causes an energy penalty in order to mitigate $\mathrm{CO}_{2}$ emissions. $\mathrm{CCS}$ has been identified as a useful and essential approach to eliminate anthropogenic $\mathrm{CO}_{2}$ emissions [100, 101], which refers to a number of technologies to capture $\mathrm{CO}_{2}$ from $\mathrm{CO}_{2}$ containing gases from processes such as combustion or gasification [102-104]. Several technologies have been attempted, including chemical absorption, physical absorption, membrane separation and other processes [71, 105]. We conduct an integrated assessment to evaluate the CCS process in the three most substantial pathways - CMTO, CBTO, and CFTO. Given that this study focuses on technical processes and the fuel emission factors are taken from literature, CCS is only applied to the gasification process and FTO process. CCS technologies integrating combustion or production of upstream fuels, such as power plant and diesel combustion, are excluded.

The CCS contains carbon capture from a mixture of gases and compression for transportation and storage [106]. In the gasification process, $\mathrm{CO}_{2}$ has been captured in the AGR unit. In that case, $\mathrm{CO}_{2}$ is captured with an adsorbent like methanol, and desorbed by stripping gas like $\mathrm{N}_{2}$. Finally, the mixture of $\mathrm{N}_{2}$ and $\mathrm{CO}_{2}$ is exhausted to atmosphere. Unlike the exhaust from $\mathrm{AGR}, \mathrm{CO}_{2}$ is required to be concentrated to save transportation energy in view of CCS [22]. In the FTO process, $\mathrm{CO}_{2}$ capture is achieved by MEA, which can be stored directly. The captured $\mathrm{CO}_{2}$ is compressed, transported to a suitable site and injected into underground reservoirs.

Herein, $\mathrm{CO}_{2}$ concentration is defined as $98 \% . \mathrm{CO}_{2}$ transportation is assumed via pipeline, and the distance is $300 \mathrm{~km} . \mathrm{CO}_{2}$ is injected into the saline aquifer at $2 \mathrm{~km}$ depth. According to the literature [106, 
107], about 5.4 MJ additional energy per $\mathrm{mol} \mathrm{CO}_{2}$ is imposed on the process. The result is depicted in Fig.

9.

It can be seen that $5.2 \mathrm{t}, 9.0 \mathrm{t}$ and $6.8 \mathrm{t} \mathrm{CO}_{2}$ per t ethylene production can be stored in the life cycle of CMTO, BMTO, and CFTO. If $\mathrm{CO}_{2}$ capture in the fuel production process (such as power generation) is considered, there will be an even greater $\mathrm{CO}_{2}$ reduction. However, more $\mathrm{CO}_{2}$ is produced due to the energy penalty for CCS. The total decrease in amounts of $\mathrm{CO}_{2}$ emissions are $4.7 \mathrm{t}, 8.2 \mathrm{t}$ and $6.2 \mathrm{t}$ in the life cycle of CMTO, BMTO and CFTO with CCS than those without CCS, respectively.

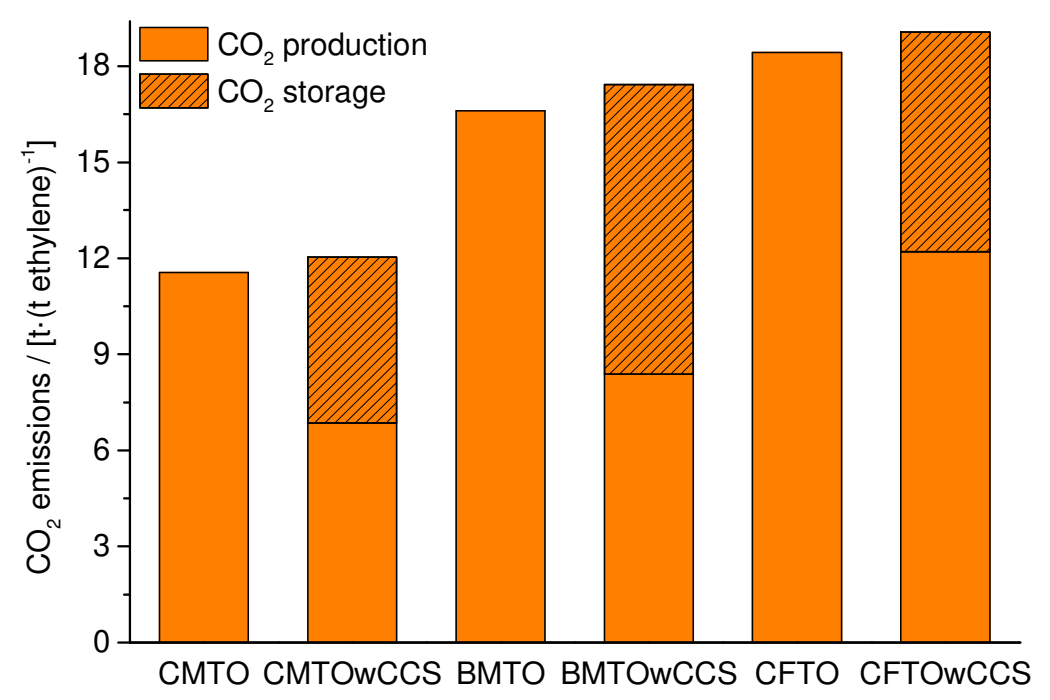

Fig. 9. Life cycle $\mathrm{CO}_{2}$ emissions compared to the processes with $\mathrm{CCS}\left(\mathrm{CO}_{2}\right.$ fixed in chemicals is not subtracted in BMTO pathway for a clear comparison).

\section{4. $\mathrm{CO}_{2}$ chemical conversion}

$\mathrm{CO}_{2}$ storage represents a powerful $\mathrm{CO}_{2}$ emissions reduction potential. Furthermore, $\mathrm{CO}_{2}$ can be used to synthesize chemicals and chemical intermediates. $\mathrm{CO}_{2}$ can be used to synthesize methanol and ethylene, which present vast carbon emissions-reducing potential, as mentioned above. Traditionally, $\mathrm{CO}_{2}$ has been 
used to produce urea and fine chemicals such as alkylene carbonates (solvent), b-oxynaphthoic acid (raw materials of dyes), salicylic acid and its derivatives (pharmaceuticals, food preservatives) [108]. However, the amount of $\mathrm{CO}_{2}$ used as a chemical feedstock corresponds to only $0.36 \%$ of global $\mathrm{CO}_{2}$ emissions, yet some processes such as $\mathrm{CO}_{2}$ to urea produce more $\mathrm{CO}_{2}$ than they can consume [65].

Nowadays, some $\mathrm{CO}_{2}$-based bulk chemicals including methane, methanol, formic acid and dimethyl carbonate have been studied [55, 60-66, 109-111], as shown in Fig. 10. $\mathrm{CO}_{2}$ can be transformed into methane, methanol, and syngas with the mixing of $\mathrm{H}_{2}$ or $\mathrm{H}_{2} \mathrm{O}$. Synthesis strategies include a great variety of methods, such as biochemical, electrochemical, thermochemical, photochemical and photoelectrochemical [57, 75-77]. Then methane, methanol, and syngas can be converted into olefins, arenes and some bulk chemicals, of which ethylene, propylene, $\mathrm{C} 4$ olefins (butene and butadiene), benzene, toluene, xylenes, and methane are chemical building blocks in the organic chemical industry [112]. Similar to $\mathrm{CCS}, \mathrm{CO}_{2}$ sources of $\mathrm{CO}_{2}$ chemical conversion can be flue gases and crude syngas. Furthermore, some researchers directly conducted conversion reaction using air as a carbon source. Kothandaraman et al. [59] reported the conversion of $\mathrm{CO}_{2}$ from air into methanol at $125-165^{\circ} \mathrm{C}$ with a highly efficient catalyst system.

Conversion of $\mathrm{CO}_{2}$ to chemicals is challenging because $\mathrm{CO}_{2}$ is stable and its reactions are highly energetically unfavourable. However, it provides a potential solution to mitigate $\mathrm{CO}_{2}$ emissions and decreases the dependence of chemical production on fossil feedstocks [65]. Trudewind et al.[58] evaluated the ecological effects of the photocatalytic conversion of $\mathrm{CO}_{2}$ to methanol and methane, the life cycle carbon emissions of which can reduce the cost of $51 \%$ than that of conventional routes adopting methane as feedstock. Hoppe et al.[113] conducted a series of LCAs of methane, methanol, syngas, polyoxymethylene, polyethylene and polypropylene derived from five different carbon source, including 
air, raw biogas, flue gas from cement plants, lignite-fired power, and municipal waste incineration plants.

It demonstrates that $\mathrm{CO}_{2}$ routes reduce the number of carbon emissions in comparison to the conventional routes to each chemical.

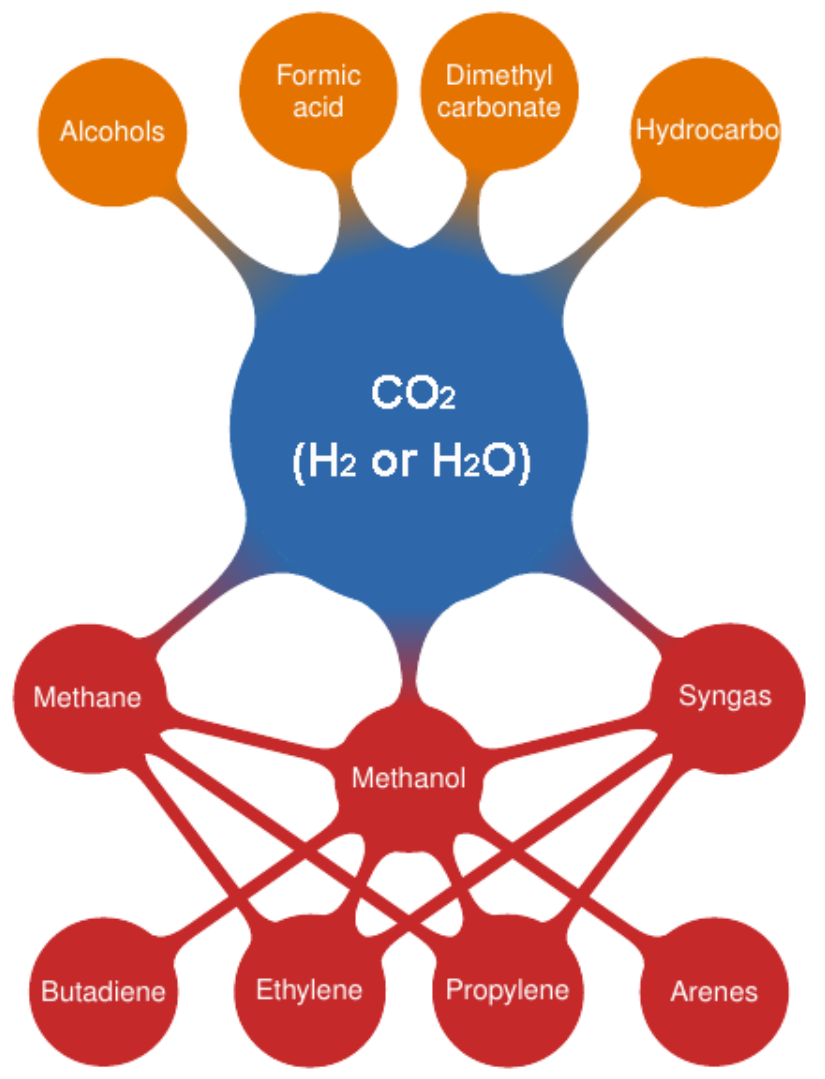

Fig. 10. Chemicals with $\mathrm{CO}_{2}$ as the feedstock.

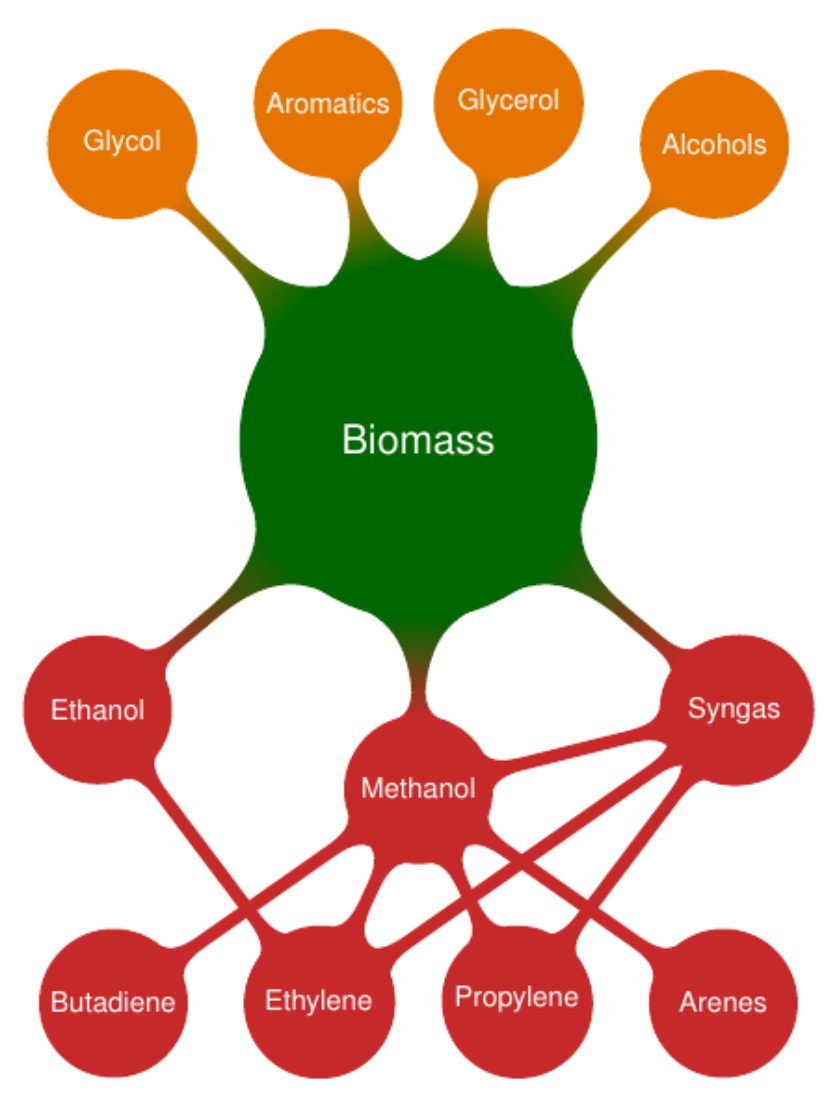

Fig. 11. Chemicals with biomass as the feedstock.

\subsection{Converting biomass resources into chemicals}

Biomass, such as energy crops, agricultural wastes, and forestry residues, are a promising alternative feedstock to produce chemicals. Crop straw, about 870 million metric tons produced in China one year [78], is still considered as agricultural waste. Straw can provide 417.6-452.4 Mt carbon materials based on 48$52 \%$ carbon content.

As described by literature [114], the biomass production process is not carbon neutral. The carbon fixed 
in chemicals is obtained from atmospheric $\mathrm{CO}_{2}$ by photosynthesis. However, $\mathrm{CO}_{2}$ emissions from cultivation, harvest, transportation, chemicals production for $\mathrm{CO}_{2}$ capture, and MTO process are from the combustion of traditional energy. For example, $2.2 \mathrm{t} \mathrm{CO}_{2}$ is emitted via BMTO pathway, even higher than the PSC pathway in this study. However, combining CCS technology, BMTO pathway possesses $7.7 \mathrm{t}$ lower $\mathrm{CO}_{2}$ emissions than that of PSC pathway. Therefore, more than 150.7 million $\mathrm{CO}_{2}$ emissions would be reduced if total ethylene is produced via BMTO with CCS in 2015, which shows a substantial $\mathrm{CO}_{2}$ emission reduction potential.

Besides methanol and ethanol, biomass can also be converted into glycol by hydrogenation [115, 116], glycerol by esterification [117], and some alcohols and aromatics such as ethyl lactate, lactic acid, acrylic acid and caprolactam by various strategies. They can act as drop-in chemicals in the current petrochemical chain [24].

Biochemicals present a lower lifecycle $\mathrm{CO}_{2}$ emissions than their fossil counterparts. Adom et al. and Hermann et al. [118] carried out a series of LCAs of propylene glycol, 1,3-propanediol, 1,4-butanediol, 3hydroxypropionic acid, acetic acid, acrylic acid, adipic acid, anhydride, caprolactam, ethanol, ethylene, ethyl lactate, isobutanol, lactic acid, lysine, polylactic acid, polyethylene, polyhydroxyalkanoates and succinic acid, the results of which show that 39 to $86 \%$ of greenhouse gases emissions can be reduced via biomass route compared to conventional pathways. If such bulky chemicals can be primarily synthesized from biomass, $\mathrm{CO}_{2}$ emissions will be drastically reduced.

\subsection{Scenario analysis for different production of ethylene}

The ethylene industry has expanded dramatically in China and will still expand in the short term. Annual production of ethylene will reach 24.1, 34.8, and 45.5 million metric tons in China in 2020, 2030, 
2040 based on increasing trend (see Section A.5 in the Appendix material). Aimed at pathways of SC, CMTO and NMTO, Chen et al.[29] conducted an energy technology roadmap and provided some policy suggestion for the ethylene industry in China. However, this work focused on a comprehensive comparison of different production pathway, in particular, sustainable pathways. Baseline and assumption are as following: the increase of ethylene production from now to 2040 is assumed to be produced via non-oil routes rather than PSC and CPP due to oil scarcity in China. In addition, a $2 \%$ energy saving by each year is set according to a linear trend in section 4.2.

Based on the above prediction analysis, this work proposes several scenarios for ethylene production. The baseline is selected as the year of 2015. In BAU (business as usual) scenario, an increase of ethylene production from now to 2040 is produced via CMTO and NMTO pathways. Based on BAU scenario, the least proportion of BMTOwCCS, CO2MTO, and BETE pathways have been calculated in BMTO scenario, CO2MTO scenario and BETE scenario for the goal of achieving the peak of $\mathrm{CO}_{2}$ emissions around 2030 in China [119]. The new technology is set to appear in 2020 to offset the period of plant design and construction. Meanwhile, it is assumed that the CCS system is added in CMTO plants from 0 to $100 \%$.
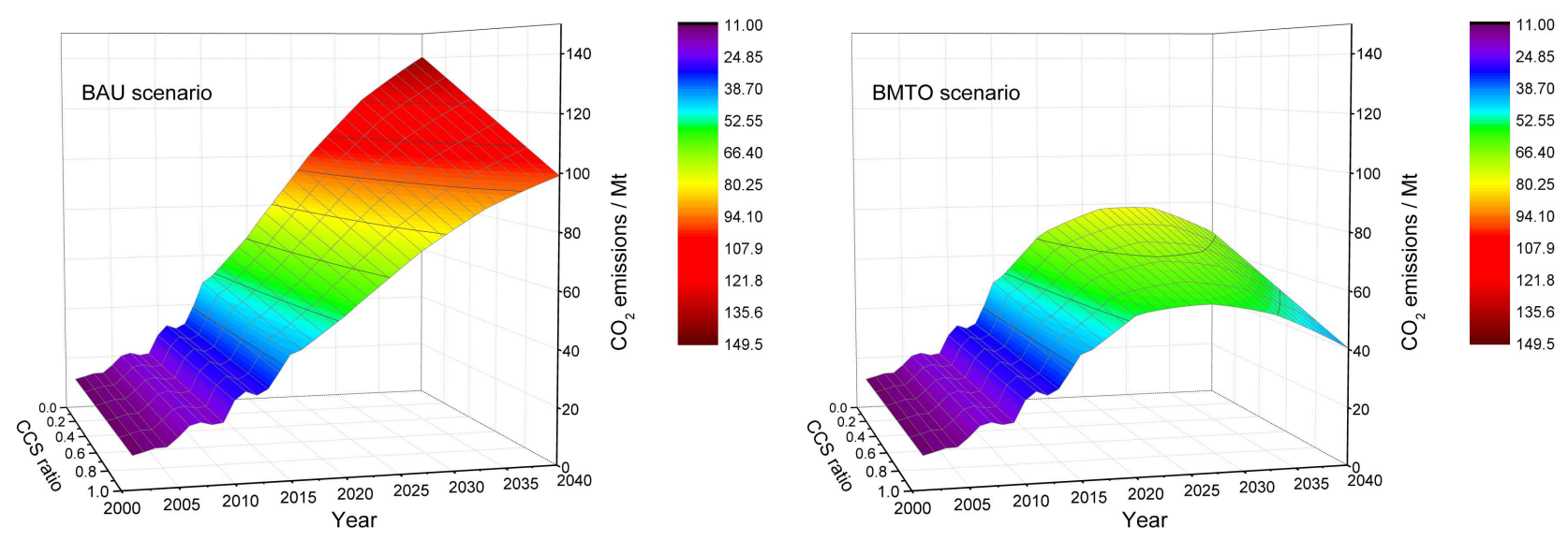

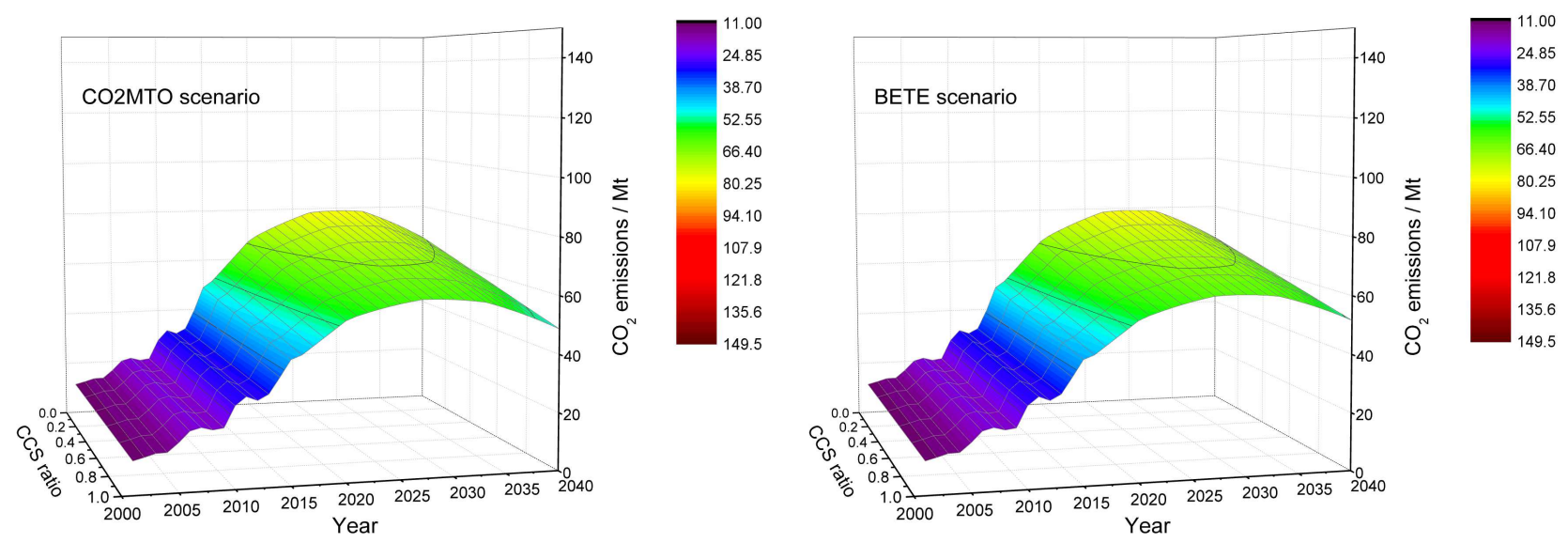

Fig. 12. $\mathrm{CO}_{2}$ emissions of ethylene production via different scenarios.

The life cycle $\mathrm{CO}_{2}$ emissions of the four scenarios are shown in Fig. 12. $\mathrm{CO}_{2}$ emissions will persistently increase with the increasing annual production from 2015 to 2040 in the $\mathrm{BAU}$ scenario. $\mathrm{CO}_{2}$ emissions will not peak in 2030 unless the ratio of BMTO, CO2MTO, and BETE pathways increase at least by $0.9 \%, 1.4 \%$, and $1.6 \%$, respectively.

From the gross $\mathrm{CO}_{2}$ emissions, more than 700 million metric tons of $\mathrm{CO}_{2}$ will be eliminated by comparing BAU scenarios with other scenarios from 2020 to 2040. While more than 1000 million metric tons of $\mathrm{CO}_{2}$ will be reduced by adopting the CCS system addition, which is about one-ninth of total carbon emissions in China in 2015 [120].

\section{Conclusions}

The low-carbon roadmap for chemical production has been depicted by integrating real-time change with different pathways in China. Ethylene has been taken as an example to predict $\mathrm{CO}_{2}$ emissions reduction in the future. The main conclusions are shown as follows: 
(i) As for lifecycle $\mathrm{CO}_{2}$ emissions of ethylene production pathways, BMTO with CCS pathway presents the least $\mathrm{CO}_{2}$ emissions, followed by $\mathrm{CO} 2 \mathrm{MTO}$, and the CFTO contributes the most $\mathrm{CO}_{2}$ emissions. From the individual contribution of each stage, the gasification process contributes the most $\mathrm{CO}_{2}$, which is the crucial factor for reducing $\mathrm{CO}_{2}$ of the life cycle of ethylene.

(ii) $\mathrm{CO}_{2}$ emissions per unit ethylene production have displayed a declining trend and decreased by $29.4 \%$ from 2000 to 2016 in China. However, the total amount of $\mathrm{CO}_{2}$ emissions continuously increase in the ethylene production industry in China.

(iii) $\mathrm{CCS}$ can dramatically reduce $\mathrm{CO}_{2}$ emissions in the chemical production process. In the life cycle of CMTO, BMTO and CFTO, $4.7 \mathrm{t}, 8.2 \mathrm{t}$ and $6.2 \mathrm{t} \mathrm{CO}_{2}$ will be reduced when producing $1.0 \mathrm{t}$ ethylene, respectively.

(iv) Use of $\mathrm{CO}_{2}$ and biomass resources is promising for $\mathrm{CO}_{2}$ emission reduction. They reduce $\mathrm{CO}_{2}$ emissions and even increase $\mathrm{CO}_{2}$ sink. Combining $\mathrm{CCS}, \mathrm{CO} 2 \mathrm{MTO}$ and $\mathrm{BMTO}$ result in $\mathrm{CO}_{2}$ emissions of $-0.05 \mathrm{t}$ and $-6.0 \mathrm{t}$ per $\mathrm{t}$ ethylene production, respectively.

(v) $\mathrm{CO}_{2}$ emissions will persistently increase unless changing chemical industry structure. The peak of $\mathrm{CO}_{2}$ emissions will be reached in 2030 when the ratio of BMTO, CO2MTO, and BETE pathways increase at least by $0.9 \%, 1.4 \%$ and $1.6 \%$, respectively. Then more than 700 million metric tons of $\mathrm{CO}_{2}$ will be eliminated from 2020 to 2040 . Therefore, it is imperative to turn to new carbon resources in the chemical industry in China, as well as increasing average technological level and to develop the technology of CCS.

\section{Policy implications}

The chemical industry has dramatically expanded during the past decades and still expand in the near 
future in China. Therefore, carbon emissions in the chemical industry will be a considerable burden and carbon emissions reduction draws the attention of researchers and governments. Some policy implications are propounded based on this study.

Technological majorization and emissions reduction strategies should be promoted in common pathways, including replacing with advanced equipment, adjusting ratios of feedstocks, improving catalyst performance, attaching emissions reduction technologies.

Carbon capture and storage should be developed in high energy-intensive processes, such as gasification process. However, it will increase the energy consumption of the process. In addition, $\mathrm{CO}_{2}$ transportation distance and injected depth are also a considered question.

Non-fossil resource should be encouraged. Biomass-based chemicals and $\mathrm{CO}_{2}$ based chemicals present a considerable potential for carbon emissions reductions, but an experiment scale and immature technologies. The government needs to enhance to provide funding support and preferential policies to the non-fossil resource.

\section{Declaration of interest}

The authors declare that there is no conflict of interest regarding the publication of this paper.

\section{Acknowledgements}

This work was financially supported by supported by the "Strategic Priority Research Program of the Chinese Academy of Sciences" Grant No. XDB17020300 and the National Natural Science Foundation of China (21690082). 


\section{References}

[1] Mousavi Babak, Lopez Neil Stephen A., Biona Jose Bienvenido Manuel, Chiu Anthony S. F., Blesl Markus. Driving forces of Iran's $\mathrm{CO}_{2}$ emissions from energy consumption: An LMDI decomposition approach. Appl Energy 2017; 206: 804-814.

[2] Wang Miao, Feng Chao. Decomposition of energy-related $\mathrm{CO}_{2}$ emissions in China: An empirical analysis based on provincial panel data of three sectors. Appl Energy 2017; 190: 772-787.

[3] Dlugokencky Ed, Tans Pieter. Trends in atmospheric carbon dioxide, http://www.esrl.noaa.gov/gmd/ccgg/trends/; 2017 [accessed 2017. 06. 14].

[4] Le Quéré C., Moriarty R., Andrew R. M., Canadell J. G., Sitch S., Korsbakken J. I., et al. Global carbon budget 2015, http://cdiac.ornl.gov/GCP/carbonbudget/2015/; 2015 [accessed 2017. 07. 10].

[5] Takht Ravanchi Maryam, Sahebdelfar Saeed. Carbon dioxide capture and utilization in petrochemical industry: potentials and challenges. Appl Petrochem Res 2014; 4(1): 63-77.

[6] Lin Boqiang, Long Houyin. Emissions reduction in China's chemical industry - Based on LMDI. Renew Sust Energ Rev 2016; 53: 1348-1355.

[7] Boulamanti Aikaterini, Moya Jose A. Production costs of the chemical industry in the EU and other countries: Ammonia, methanol and light olefins. Renew Sust Energ Rev 2017; 68: 1205-12.

[8] Yao Yuan, Graziano Diane J., Riddle Matthew, Cresko Joe, Masanet Eric. Understanding variability to reduce the energy and GHG footprints of U.S. ethylene production. Environ Sci Technol 2015; 49(24): 14704-16.

[9] Hong Jinglan, Zhang Yanlu, Xu Xu, Li Xiangzhi. Life cycle assessment of corn- and cassava-based ethylene production. Biomass Bioenergy 2014; 67(0): 304-11.

[10] Lee Yun-Jo, Park Jo-Yong, Jun Ki-Won, Bae Jong Wook, Viswanadham Nagabhatla. Enhanced production of $\mathrm{C}_{2}-\mathrm{C}_{4}$ olefins directly from synthesis gas. Catal Lett 2008; 126(1-2): 149-54.

[11] Qian Bozhang. Ethylene market and raw material supply in China. Sino-global Energy 2011; 16(6): 62-73 [in Chinese].

[12] Luo Hongjing, Lu Xiaodong, Yang Guiying, Yang Xiuxia, Zhao Rui. 2015 review and 2016 outlook of global petrochemical industry. International Petroleum Economics 2016; 24(5): 50-59 [in Chinese].

[13] Qian Bozhang. Technology review and market analysis on petrochemical industry (2008-2011). Petroleum Industry Press; 2011 [in Chinese].

[14] Ministry of Industry and Information Technology of the People's Republic of China. Petrochemical and chemical industry development planning (2016-2020) http://www.miit.gov.cn/n1146295/n1652858/n1652930/n3757017/c5285161/content.html; 2016 [accessed 2017. 09. 30][In Chinese].

[15] Torres Galvis Hirsa M., de Jong Krijn P. Catalysts for Production of Lower Olefins from Synthesis Gas: A Review. ACS Catal 2013; 3(9): 2130-2149.

[16] Tian Peng, Wei Yingxu, Ye Mao, Liu Zhongmin. Methanol to olefins (MTO): From fundamentals to commercialization. ACS Catal 2015; 5(3): 1922-38.

[17] Xiang Dong, Qian Yu, Man Yi, Yang Siyu. Techno-economic analysis of the coal-to-olefins process 
in comparison with the oil-to-olefins process. Appl Energy 2014; 113: 639-647.

[18] Zhang Qun, Hu Shanying, Chen Dingjiang. A comparison between coal-to-olefins and oil-based ethylene in China: An economic and environmental perspective. J Cleaner Prod 2017; 165: 13511360.

[19] Xiang Dong, Yang Siyu, Li Xiuxi, Qian Yu. Life cycle assessment of energy consumption and GHG emissions of olefins production from alternative resources in China. Energy Convers Manage 2015; 90(0): 12-20.

[20] Chen Qianqian, Lv Min, Wang Danfeng, Tang Zhiyong, Wei Wei, Sun Yuhan. Eco-efficiency assessment for global warming potential of ethylene production processes: A case study of China. $\mathbf{J}$ Cleaner Prod 2017; 142: 3109-16.

[21] He Chang, You Fengqi. Deciphering the true life cycle environmental impacts and costs of the mega-scale shale gas-to-olefins projects in the United States. Energy Environ Sci 2016; 9(3): 82040.

[22] Xiang Dong, Yang Siyu, Liu Xia, Mai Zihao, Qian Yu. Techno-economic performance of the coalto-olefins process with CCS. Chem Eng J 2014; 240(0): 45-54.

[23] Yang Y., Brammer J. G., Wright D. G., Scott J. A., Serrano C., Bridgwater A. V. Combined heat and power from the intermediate pyrolysis of biomass materials: performance, economics and environmental impact. Applied Energy 2017; 191: 639-652.

[24] Lanzafame Paola, Centi Gabriele, Perathoner Siglinda. Catalysis for biomass and $\mathrm{CO}_{2}$ use through solar energy: opening new scenarios for a sustainable and low-carbon chemical production. Chem Soc Rev 2014; 43(22): 7562-80.

[25] Liptow Christin, Tillman Anne-Marie, Janssen Matty. Life cycle assessment of biomass-based ethylene production in Sweden - is gasification or fermentation the environmentally preferable route? Int J Life Cycle Assess 2015; 20(5): 632-44.

[26] Ghanta Madhav, Fahey Darryl, Subramaniam Bala. Environmental impacts of ethylene production from diverse feedstocks and energy sources. Appl Petrochem Res 2013; 4(2): 167-179.

[27] Ren Tao, Patel Martin K., Blok Kornelis. Steam cracking and methane to olefins: Energy use, $\mathrm{CO}_{2}$ emissions and production costs. Energy 2008; 33(5): 817-33.

[28] Ren Tao, Patel Martin K. Basic petrochemicals from natural gas, coal and biomass: Energy use and CO2 emissions. Resour Conserv Recycl 2009; 53(9): 513-528.

[29] Chen Jing-Ming, Yu Biying, Wei Yi-Ming. Energy technology roadmap for ethylene industry in China. Appl Energy 2018; 224: 160-174.

[30] U.S. Energy Information Agency (EIA). Natural gas gross withdrawals and production, https://www.eia.gov/dnav/ng/ng_prod_sum_dc_NUS_mmcf_a.htm; 2017 [accessed 2017. 07. 14].

[31] Liptow Christin, Tillman Anne-Marie, Janssen Matty, Wallberg Ola, Taylor Glenn A. Ethylene based on woody biomass-what are environmental key issues of a possible future Swedish production on industrial scale. Int J Life Cycle Assess 2013; 18(5): 1071-1081.

[32] ISO14040, Environmental management - Life cycle assessment - Principle and framework. 2006.

[33] Hellweg Stefanie, Milà i Canals Llorenç. Emerging approaches, challenges and opportunities in life cycle assessment. Science 2014; 344(6188): 1109-13.

[34] Haupt Melanie, Kägi Thomas, Hellweg Stefanie. Life cycle inventories of waste management processes. Data in Brief 2018; 19: 1441-1457.

[35] Esnouf A., Latrille E., Steyer J. P., Helias A. Representativeness of environmental impact 
assessment methods regarding Life Cycle Inventories. Sci Total Environ 2018; 621: 1264-1271.

[36] GalvanizeIt. Life-cycle inventory \& life-cycle assessment, https://galvanizeit.org/sustainabledevelopment-hot-dip-galvanizing-online-seminar/what-is-sustainable-development/life-cycleinventory-life-cycle-assessment; [accessed 2018. 07.20].

[37] Hong Jingmin, Zhou Jing, Hong Jinglan. Comparative study of life cycle environmental and economic impact of corn- and corn stalk-based-ethanol production. Journal of Renewable and Sustainable Energy 2015; 7(2): 023106.

[38] Li Xin, Ou Xunmin, Zhang Xu, Zhang Qian, Zhang Xiliang. Life-cycle fossil energy consumption and greenhouse gas emission intensity of dominant secondary energy pathways of China in 2010 . Energy 2013; 50(0): 15-23.

[39] Zhao Zhitong, Liu Yong, Wang Feng, Li Xuekuan, Deng Shuping, Xu Jie, et al. Life cycle assessment of primary energy demand and greenhouse gas (GHG) emissions of four propylene production pathways in China. J Cleaner Prod 2017; 163: 285-292.

[40] Department of Energy Statistics. National Bureau of Statistics. People's Republic of China. China energy statistical yearbook 2013. Beijing: China Statistics Press; 2014 [in Chinese].

[41] Sinopec, GB/T 50441-2007. Standard for calculation of energy consumption in petrochemical engineering design. 2007 [in Chinese].

[42] National Development and Reform Commission. Guidelines for the preparation of provincial greenhouse gas inventory 2011 [in Chinese].

[43] Intergovernmental Panel on Climate Change. 2006 IPCC guidelines for national greenhouse gas inventories. IGES, Japan; 2006.

[44] Liu Zhu, Guan Dabo, Wei Wei, Davis Steven J., Ciais Philippe, Bai Jin, et al. Reduced carbon emission estimates from fossil fuel combustion and cement production in China. Nature 2015; 524(7565): 335-38.

[45] Lu Xiaodong. A review of world and China's ethylene industry in 2015 and an outlook for 2016. Petroleum \& Petrochemical Today 2016; 24(4): 19-24 [in Chinese].

[46] Ma Guofeng, Xue Yuehua, Guo Xin. A review of ethylene production in Sinopec in 2014. Ethylene Industry 2015(1): 1-5 [in Chinese].

[47] China Ethylene Industry Association. China ethylene industry association, http://www.ethylenenet.com.cn/; 2015 [accessed 2015. 10. 10][In Chinese].

[48] Fattouh Bassam, Brown Craig. US NGLs production and steam cracker substitution: What will the spillover effects be in global petrochemical markets?, https://www.oxfordenergy.org/publications/us-ngls-production-and-steam-cracker-substitutionwhat-will-the-spillover-effects-be-in-a-global-petrochemicals-market/; 2014 [accessed 2017. 07. 10].

[49] Brooks Robert E. Modeling the north american market for natural gas liquids, http://www.usaee.org/usaee2013/submissions/OnlineProceedings/USAEE2013.NGLNA.31may13 .v2.pdf; 2013 [accessed 2017. 07. 10].

[50] Wang Dazhuang, Wang Hezhou, Xie Chaogang, Wu Lei. Commercial trial of CPP complete technology for producing light olefins from heavy feedstock. Petroleum Processing and Petrochemicals 2013; 44(1): 56-59 [in Chinese].

[51] Zhu Genquan, Xie Chaogang. Research and commercial application of CPP technology for producing light olefins from heavy oil. China Pet Process PE 2013; 15(3): 7-12. 
[52] Wang Zizong. Production technology and economy analysis of ethylene and propylene. Beijing: China Petrochemical Press; 2015 [in Chinese].

[53] Olsbye Unni, Svelle Stian, Bjørgen Morten, Beato Pablo, Janssens Ton V. W., Joensen Finn, et al. Conversion of methanol to hydrocarbons: How zeolite cavity and pore size controls product selectivity. Angew Chem Int Ed 2012; 51(24): 5810-31.

[54] Ali Khozema Ahmed, Abdullah Ahmad Zuhairi, Mohamed Abdul Rahman. Recent development in catalytic technologies for methanol synthesis from renewable sources: A critical review. Renew Sust Energ Rev 2015; 44: 508-18.

[55] Aresta M., Dibenedetto A. Utilisation of $\mathrm{CO}_{2}$ as a chemical feedstock: opportunities and challenges. Dalton Trans 2007(28): 2975-92.

[56] Renó Maria Luiza Grillo, Lora Electo Eduardo Silva, Palacio José Carlos Escobar, Venturini Osvaldo José, Buchgeister Jens, Almazan Oscar. A LCA (life cycle assessment) of the methanol production from sugarcane bagasse. Energy 2011; 36(6): 3716-26.

[57] Kim Jiyong, Henao Carlos A., Johnson Terry A., Dedrick Daniel E., Miller James E., Stechel Ellen B., et al. Methanol production from $\mathrm{CO}_{2}$ using solar-thermal energy: process development and techno-economic analysis. Energy Environ Sci 2011; 4(9): 3122-32.

[58] Trudewind Clemens A., Schreiber Andrea, Haumann David. Photocatalytic methanol and methane production using captured $\mathrm{CO}_{2}$ from coal-fired power plants. Part I - a Life Cycle Assessment. J Cleaner Prod 2014; 70: 27-37.

[59] Kothandaraman J., Goeppert A., Czaun M., Olah G. A., Prakash G. K. Surya. Conversion of $\mathrm{CO}_{2}$ from air into methanol using a polyamine and a homogeneous ruthenium catalyst. J Am Chem Soc 2016; 138(3): 778-81.

[60] Yuan Lan, Xu Yi-Jun. Photocatalytic conversion of $\mathrm{CO}_{2}$ into value-added and renewable fuels. Appl Surf Sci 2015; 342: 154-67.

[61] Peters Martina, Köehler Burkhard, Kuckshinrichs Wilhelm, Leitner Walter, Markewitz Peter, Mueller Thomas E. Chemical technologies for exploiting and recycling carbon dioxide into the value chain. ChemSusChem 2011; 4(9): 1216-40.

[62] Havran Vesna, Duduković Milorad P., Lo Cynthia S. Conversion of methane and carbon dioxide to higher value products. Ind Eng Chem Res 2011; 50(12): 7089-00.

[63] Wang Wei, Wang Shengping, Ma Xinbin, Gong Jinlong. Recent advances in catalytic hydrogenation of carbon dioxide. Chem Soc Rev 2011; 40(7): 3703-27.

[64] Zangeneh Farnaz Tahriri, Sahebdelfar Saeed, Ravanchi Maryam Takht. Conversion of carbon dioxide to valuable petrochemicals: An approach to clean development mechanism. J Nat Gas Chem 2011; 20(3): 219-31.

[65] Otto Alexander, Grube Thomas, Schiebahn Sebastian, Stolten Detlef. Closing the loop: Captured $\mathrm{CO}_{2}$ as a feedstock in the chemical industry. Energy Environ Sci 2015; 8(11): 3283-97.

[66] Porosoff Marc D., Yan Binhang, Chen Jingguang G. Catalytic reduction of $\mathrm{CO}_{2}$ by $\mathrm{H}_{2}$ for synthesis of CO, methanol and hydrocarbons: challenges and opportunities. Energy Environ Sci 2016; 9(1): 62-73.

[67] Xiang Dong, Yang Siyu, Qian Yu. Techno-economic analysis and comparison of coal based olefins processes. Energy Convers Manage 2016; 110: 33-41.

[68] Yang Sheng, Qian Yu, Yang Siyu. Development of a full $\mathrm{CO}_{2}$ capture process based on the rectisol wash technology. Ind Eng Chem Res 2016; 55(21): 6186-93. 
[69] Sun Li, Smith Robin. Rectisol wash process simulation and analysis. J Cleaner Prod 2013; 39(0): 321-28.

[70] Hugill J. A., Overbeek J. P, Spoelstra S. A comparison of the eco-efficiency of two production routes for methanol. The Netherlands: Netherlands Energy Research Foundation; 2001.

[71] D'Alessandro D. M., Smit B., Long J. R. Carbon dioxide capture: prospects for new materials. Angew Chem Int Ed 2010; 49(35): 6058-82.

[72] Rochelle Gary T. Amine scrubbing for $\mathrm{CO}_{2}$ capture. Science 2009; 325(5948): 1652-54.

[73] Pehnt Martin, Henkel Johannes. Life cycle assessment of carbon dioxide capture and storage from lignite power plants. Int J Greenh Gas Con 2009; 3(1): 49-66.

[74] Hurst Thomas F., Cockerill Timothy T., Florin Nicholas H. Life cycle greenhouse gas assessment of a coal-fired power station with calcium looping $\mathrm{CO}_{2}$ capture and offshore geological storage. Energy Environ Sci 2012; 5(5): 7132-50.

[75] Jadhav Suhas G., Vaidya Prakash D., Bhanage Bhalchandra M., Joshi Jyeshtharaj B. Catalytic carbon dioxide hydrogenation to methanol: A review of recent studies. Chem Eng Res Des 2014; 92(11): 2557-67.

[76] Wang W., Himeda Y., Muckerman J. T., Manbeck G. F., Fujita E. $\mathrm{CO}_{2}$ hydrogenation to formate and methanol as an alternative to photo- and electrochemical $\mathrm{CO}_{2}$ reduction. Chem Rev 2015; 115(23): 12936-73.

[77] Ganesh Ibram. Conversion of carbon dioxide into methanol - a potential liquid fuel: Fundamental challenges and opportunities (a review). Renew Sust Energ Rev 2014; 31: 221-57.

[78] China National Renewable Energy Centre. The renewable energy industry development report 2015. Beijing: China Economic Press; 2015.

[79] Yang Qing, Han Fei, Chen Yingquan, Yang Haiping, Chen Hanping. Greenhouse gas emissions of a biomass-based pyrolysis plant in China. Renewable and Sustainable Energy Reviews 2016; 53: 1580-1590.

[80] Qiu Xinhong. Characteristics analysis of biomass pyrolysis and gasification. Energy Conservation 2014; 381(6): 28-31 [in Chinese].

[81] Xiang Yangyang, Zhou Jingsong, Lin Bowen, Xue Xiaoao, Tian Xingtao, Luo Zhongyang. Exergetic evaluation of renewable light olefins production from biomass via synthetic methanol. Applied Energy 2015; 157: 499-507.

[82] Abdelouahed L., Authier O., Mauviel G., Corriou J. P., Verdier G., Dufour A. Detailed Modeling of Biomass Gasification in Dual Fluidized Bed Reactors under Aspen Plus. Energy \& Fuels 2012; 26(6): 3840-3855.

[83] Zhang Yanan, Xiao Jun, Shen Laihong. Simulation of Methanol Production from Biomass Gasification in Interconnected Fluidized Beds. Industrial \& Engineering Chemistry Research 2009; 48(11): 5351-5359.

[84] Chen D., Moljord K., Holmen A. A methanol to olefins review: Diffusion, coke formation and deactivation on SAPO type catalysts. Microporous Mesoporous Mat 2012; 164(0): 239-50.

[85] Che Yinping. Comparison of MTP and MTO technology Science \& Technology Information 2012(31): 84,87 [in Chinese].

[86] SYN Energy Technology CO. LTD. Operating conditions and product distribution of MTO, http://www.syn.ac.cn/doshow1.php?id=26; 2011 [accessed 2015. 07. 09][in Chinese].

[87] Torres Galvis H. M., Bitter J. H., Khare C. B., Ruitenbeek M., Dugulan A. I., de Jong K. P. 
Supported iron nanoparticles as catalysts for sustainable production of lower olefins. Science 2012; 335(6070): 835-38.

[88] Zhong Liangshu, Yu Fei, An Yunlei, Zhao Yonghui, Sun Yuhan, Li Zhengjia, et al. Cobalt carbide nanoprisms for direct production of lower olefins from syngas. Nature 2016; 538(7623): 84-87.

[89] Torres Galvis H. M., Bitter J. H., Davidian T., Ruitenbeek M., Dugulan A. I., de Jong K. P. Iron particle size effects for direct production of lower olefins from synthesis gas. J Am Chem Soc 2012; 134(39): 16207-15.

[90] Cheng K., Gu B., Liu X., Kang J., Zhang Q., Wang Y. Direct and highly selective conversion of synthesis gas into lower olefins: Design of a bifunctional catalyst combining methanol synthesis and carbon-carbon coupling. Angew Chem Int Ed 2016; 55(15): 4725-28.

[91] Jiao Feng, Li Jinjing, Pan Xiulian, Xiao Jianping, Li Haobo, Ma Hao, et al. Selective conversion of syngas to light olefins. Science 2016; 351(6277): 1065-68.

[92] Zhang Minhua, Yu Yingzhe. Dehydration of ethanol to ethylene. Ind Eng Chem Res 2013; 52(28): 9505-14.

[93] Morschbacker Antonio. Bio-ethanol based ethylene. Polym Rev 2009; 49(2): 79-84.

[94] Wei Ping, Cheng Lihua, Zhang Lin, Xu Xinhua, Chen Huanlin, Gao Congjie. A review of membrane technology for bioethanol production. Renew Sust Energ Rev 2014; 30: 388-400.

[95] Nigam Poonam Singh, Singh Anoop. Production of liquid biofuels from renewable resources. Progress in Energy and Combustion Science 2011; 37(1): 52-68.

[96] Munoz I., Flury K., Jungbluth N., Rigarlsford G., Canals L. M. I., King H. Life cycle assessment of bio-based ethanol produced from different agricultural feedstocks. International Journal of Life Cycle Assessment 2014; 19(1): 109-119.

[97] Jonker J. G. G., van der Hilst F., Junginger H. M., Cavalett O., Chagas M. F., Faaij A. P. C. Outlook for ethanol production costs in Brazil up to 2030, for different biomass crops and industrial technologies. Applied Energy 2015; 147: 593-610.

[98] Yang Q., Chen G. Q. Greenhouse gas emissions of corn-ethanol production in China. Ecological Modelling 2013; 252: 176-184.

[99] The Central People's Government of the People's Republic of China. The 11th five-year plan for energy conservation and emissions reduction review: Energy conservation and emissions reduction achieved significant results, http://www.gov.cn/gzdt/2011-03/10/content_1821714.htm; 2011 [accessed 2017. 04. 15][in Chinese].

[100] Aminu Mohammed D., Nabavi Seyed Ali, Rochelle Christopher A., Manovic Vasilije. A review of developments in carbon dioxide storage. Appl Energy 2017: 10.1016/j.apenergy.2017.09.015.

[101] Lee Suh-Young, Lee Jae-Uk, Lee In-Beum, Han Jeehoon. Design under uncertainty of carbon capture and storage infrastructure considering cost, environmental impact, and preference on risk. Appl Energy 2017; 189: 725-738.

[102] Markewitz Peter, Kuckshinrichs Wilhelm, Leitner Walter, Linssen Jochen, Zapp Petra, Bongartz Richard, et al. Worldwide innovations in the development of carbon capture technologies and the utilization of $\mathrm{CO}_{2}$. Energy Environ Sci 2012; 5(6): 7281-305.

[103] Boot-Handford Matthew E., Abanades Juan C., Anthony Edward J., Blunt Martin J., Brandani Stefano, Mac Dowell Niall, et al. Carbon capture and storage update. Energy Environ Sci 2014; 7(1): 130-89.

[104] Intergovernmental Panel on Climate Change, IPCC special report on carbon dioxide capture and 
storage. 2005, Cambridge University Press.

[105] Leung Dennis Y. C., Caramanna Giorgio, Maroto-Valer M. Mercedes. An overview of current status of carbon dioxide capture and storage technologies. Renew Sust Energ Rev 2014; 39: 426-43.

[106] House Kurt Zenz, Harvey Charles F., Aziz Michael J., Schrag Daniel P. The energy penalty of postcombustion $\mathrm{CO}_{2}$ capture \& storage and its implications for retrofitting the U.S. installed base. Energy Environ Sci 2009; 2(2): 193-205.

[107] Odeh Naser A., Cockerill Timothy T. Life cycle GHG assessment of fossil fuel power plants with carbon capture and storage. Energy Policy 2008; 36(1): 367-80.

[108] Omae Iwao. Aspects of carbon dioxide utilization. Catal Today 2006; 115(1-4): 33-52.

[109] Yu K. M. K., Curcic I., Gabriel J., Tsang S. C. E. Recent advances in $\mathrm{CO}_{2}$ capture and utilization. ChemSusChem 2008; 1(11): 893-99.

[110] Wong Wing-Leung, Lee Lawrence Yoon Suk, Ho Kam-Piu, Zhou Zhong-Yuan, Fan Ting, Lin Zhenyang, et al. A green catalysis of $\mathrm{CO}_{2}$ fixation to aliphatic cyclic carbonates by a new ionic liquid system. Appl Catal, A 2014; 472: 160-66.

[111] Thomas John Meurig, Harris Kenneth D. M. Some of tomorrow's catalysts for processing renewable and non-renewable feedstocks, diminishing anthropogenic carbon dioxide and increasing the production of energy. Energy Environ Sci 2016; 9(3): 687-708.

[112] Wittcoff Harold A., Reuben Bryan G., Plotkin Jeffrey S. Industrial organic chemicals, 3rd ed. Hoboken: John Wiley \& Sons, Inc.; 2013.

[113] Hoppe Wieland, Thonemann Nils, Bringezu Stefan. Life cycle assessment of carbon dioxide-based production of methane and methanol and derived polymers. J Ind Ecol 2018; 22(2): 327-340.

[114] Nian Victor. The carbon neutrality of electricity generation from woody biomass and coal, a critical comparative evaluation. Appl Energy 2016; 179: 1069-1080.

[115] Ji Na, Zhang Tao, Zheng Mingyuan, Wang Aiqin, Wang Hui, Wang Xiaodong, et al. Catalytic conversion of cellulose into ethylene glycol over supported carbide catalysts. Catalysis Today 2009; 147(2): 77-85.

[116] Yue Hairong, Zhao Yujun, Ma Xinbin, Gong Jinlong. Ethylene glycol: properties, synthesis, and applications. Chem Soc Rev 2012; 41(11): 4218-44.

[117] Brandner A., Lehnert K., Bienholz A., Lucas M., Claus P. Production of Biomass-Derived Chemicals and Energy: Chemocatalytic Conversions of Glycerol. Topics in Catalysis 2009; 52(3): 278-287.

[118] Hermann B. G., Blok K., Patel M. K. Producing bio-based bulk chemicals using industrial biotechnology saves energy and combats climate change. Environmental Science \& Technology 2007; 41(22): 7915-7921.

[119] The White House Office of the Press Secretary. U.S.-China joint announcement on climate change, https://www.whitehouse.gov/the-press-office/2014/11/11/us-china-joint-announcement-climatechange; 2014 [accessed 2017. 06. 15].

[120] British Petroleum, BP Statistical Review of World Energy 2017. 2017. 